STEVEN J. DAVIS

University of Chicago

TILL VON WACHTER

Columbia University

\title{
Recessions and the Costs of Job Loss
}

ABSTRACT We develop new evidence on the cumulative earnings losses associated with job displacement, drawing on longitudinal Social Security records from 1974 to 2008. In present-value terms, men lose an average of 1.4 years of predisplacement earnings if displaced in mass-layoff events that occur when the national unemployment rate is below 6 percent. They lose a staggering 2.8 years of predisplacement earnings if displaced when the unemployment rate exceeds 8 percent. These results reflect discounting at a 5 percent annual rate over 20 years after displacement. We also document large cyclical movements in the incidence of job loss and job displacement and present evidence on how worker anxieties about job loss, wage cuts, and job opportunities respond to contemporaneous economic conditions. Finally, we confront leading models of unemployment fluctuations with evidence on the present-value earnings losses associated with job displacement. The 1994 model of Dale Mortensen and Christopher Pissarides, extended to include search on the job, generates present-value losses that are only one-fourth as large as observed losses. Moreover, present-value losses in the model vary little with aggregate conditions at the time of displacement, unlike the pattern in the data.

ajor economic downturns bring large increases in permanent layoffs among workers with long tenure on the job. We refer to this type of job loss event as a displacement. Previous research shows that job displacements lead to large and persistent earnings losses for the affected workers. ${ }^{1}$ The available evidence also indicates that job displacement

1. See, for example, Jacobson, Lalonde, and Sullivan (1993), Couch and Placzek (2010), and von Wachter, Song, and Manchester (2011). 
leads to less stability in earnings and employment, worse health outcomes, higher mortality, lower educational achievement by the children of displaced workers, and other unwelcome consequences. ${ }^{2}$

We develop new evidence on the cumulative earnings losses associated with job displacement and the role of labor market conditions at the time of displacement. In present-value terms, men lose an average of 1.4 years of predisplacement earnings if displaced in mass-layoff events that occur when the national unemployment rate is below 6 percent. They lose a staggering 2.8 years of predisplacement earnings if displaced when the unemployment rate exceeds 8 percent. These results reflect discounting at a 5 percent annual rate over 20 years after displacement. We also document large cyclical movements in the incidence of job loss and job displacement, and we investigate how worker anxieties about job loss, wage cuts, and other labor market prospects respond to contemporaneous economic conditions. Finally, we confront leading models of unemployment fluctuations in the tradition of work by Peter Diamond, Dale Mortensen, and Christopher Pissarides with evidence on the present-value earnings losses associated with job displacement.

Our study builds on three major areas of research: empirical work on cyclical fluctuations in job destruction, job loss, and unemployment; empirical work on earnings losses and other outcomes associated with job displacement; and theoretical work on search-and-matching models of unemployment fluctuations along the lines of Mortensen and Pissarides (1994). In terms of a broad effort to bring together these areas of research, the closest antecedent to our study is that by Robert Hall (1995). In terms of its effort to confront equilibrium search-and-matching models with evidence on the earnings losses associated with job displacement, the closest prior work is that by Wouter Den Haan, Garey Ramey, and Joel Watson (2000).

Our empirical investigation of the earnings losses associated with job displacement draws heavily on recent research by von Wachter, Jae Song, and Joyce Manchester (2011). They develop new evidence on the shortand long-term earnings effects of job loss using longitudinal Social Security records covering more than 30 years. Our first main contribution is to characterize, drawing on their estimated empirical models, how presentvalue earnings losses due to job displacement vary with business cycle

2. We review the evidence and provide citations to the relevant literature in section III. See also von Wachter (2010). 
conditions at the time of displacement. For men with 3 or more years of job tenure who lose jobs in mass-layoff events at larger firms, job displacement reduces the present value of future earnings by 12 percent in an average year. The present-value losses are high in all years, but they rise steeply with the unemployment rate in the year of displacement. Presentvalue losses for displacements that occur in recessions are nearly twice as large as for displacements in expansions. The entire future path of earnings losses is much higher for displacements that occur in recessions. In short, the present-value earnings losses associated with job displacement are very large, and they are highly sensitive to labor market conditions at the time of displacement.

Drawing on data from the General Social Survey of the National Opinion Research Center and from Gallup polling, we also examine the relationship of anxieties about job loss, wage cuts, ease of job finding, and other labor market prospects to actual labor market conditions. The available evidence indicates that cyclical fluctuations in worker perceptions and anxieties track actual labor market conditions rather closely, and that they respond quickly to deteriorations in the economic outlook. The Gallup data, in particular, show a tremendous increase in worker anxieties about labor market prospects after the peak of the financial crisis in 2008 and 2009. They also show a recent return to the same high levels of anxiety. These data suggest that fears about job loss and other negative labor market outcomes are themselves a significant and costly aspect of economic downturns for a broad segment of the population. These findings also imply that workers are well aware of and concerned about the costly nature of job loss, especially in recessions.

Our second main contribution is to analyze whether leading theoretical models of unemployment fluctuations can account for our evidence on the magnitude and cyclicality of present-value earnings losses associated with job displacement. Following Hall and Paul Milgrom (2008), we consider three variants of the basic Mortensen-Pissarides model analyzed by Robert Shimer (2005) and many others. We also consider a richer model by Simon Burgess and Hélène Turon (2010) that introduces search on the job and replacement hiring into the model of Mortensen and Pissarides (1994). The richer model generates worker flows apart from job flows, heterogeneity in productivity and match surplus values, and recessionary spikes in job destruction, job loss, and unemployment inflows of the sort we see in the data.

The search-and-matching models we consider do not account for our evidence on the present-value earnings losses associated with job displacement. 
The empirical losses are an order of magnitude larger than those implied by basic versions of the Mortensen-Pissarides model. Wage rigidity of the form considered by Hall and Milgrom (2008) greatly improves the model's ability to explain aggregate unemployment fluctuations, but it does not bring the model closer to evidence on the earnings losses associated with displacement. The model of Burgess and Turon (2010) generates larger present-value losses, because most job-losing workers in the model do not immediately recover predisplacement wage levels upon reemployment. Instead, unemployed persons tend to flow into jobs on the lower rungs of the wage distribution and move up the distribution over time. Yet when calibrated for consistency with U.S. unemployment flows, the model of Burgess and Turon yields presentvalue earnings losses due to job loss less than one-fourth as large as the empirical losses. Moreover, present-value losses in the model vary little with aggregate conditions at the time of displacement, unlike the pattern in the data.

Present-value income (as opposed to earnings) losses associated with job loss are even smaller in the search models we consider. Indeed, a fundamental weakness of these models is their implication that job loss is a rather inconsequential event from the perspective of individual welfare. In this sense, and despite many virtues and attractions, this class of models fails to address a central reason that job loss, unemployment, and recessions attract so much attention and concern from economists, policymakers, and others. For the same reason, care should be taken in using this class of models to form conclusions about the welfare effects of shocks and government policies.

The paper proceeds as follows. Section I presents evidence on the incidence of job destruction, layoffs, unemployment inflows, and job displacement over the business cycle. Section II first summarizes previous research on the short- and long-term consequences of job displacements for earnings. It then draws on work by von Wachter and others (2011) to estimate near-term and present-value earnings losses associated with job displacement, and to investigate how the losses vary with business cycle conditions at displacement. Section III reviews previous work on the nonmonetary costs of displacement and presents evidence on cyclical fluctuations in perceptions and anxieties related to labor market prospects. Section IV considers selected equilibrium search-and-matching models of unemployment fluctuations and evaluates their implications for the earnings and income losses associated with job loss. Section V concludes. 


\section{The Incidence of Job Loss and Job Displacement over Time}

Figure 1 displays four time series that draw on different sources of data and pertain to different concepts of job loss. The job destruction measure captures gross employment losses summed over shrinking and closing establishments in the Business Employment Dynamics (BED) database. ${ }^{3}$ The layoff measure reflects data on employer-initiated separations, as reported by employers in the Job Openings and Labor Turnover Survey (JOLTS) and as aggregated and extended back to 1990 by Davis, Jason Faberman, and John Haltiwanger (2012). ${ }^{4}$ We calculate unemployment inflow rates using monthly Current Population Survey (CPS) data on the number of employed persons and the number unemployed less than 5 weeks. Summing over months yields the quarterly rates. The measure of initial unemployment insurance (UI) claims is the quarterly sum of weekly new claims for UI benefits, expressed as a percent of nonfarm payroll employment.

Figure 1 highlights two key points. First, the sheer volume of job loss and unemployment incidence is enormous - in good economic times and bad. For example, the JOLTS-based layoff rate averages 7 percent per quarter from 1990 to 2011. Multiplying this figure by nonfarm payroll employment in 2011 yields about 9 million layoffs per quarter. Quarterly averages for job destruction and unemployment inflows are of similar magnitude. Initial UI claims average about 5 million per quarter. In short, the U.S. economy routinely accommodates huge numbers of lost jobs and unemployment spells.

Many, perhaps most, of these job loss events involve little financial loss or other hardship for individuals and families. Indeed, the high rates shown in figure 1 reflect an impressive capacity for constant renewal and productivity-enhancing reallocation of jobs, workers, and capital in the economy as a whole..$^{5}$ It is important to keep this point in mind when interpreting

3. The BED contains longitudinally linked records for all businesses covered by state unemployment insurance agencies, making it virtually a census of nonfarm private business establishments.

4. To deal with weaknesses in the JOLTS sample design, Davis and others (2012) rely on BED data to track the cross-sectional distribution of establishment-level growth rates over time. They combine micro data from the BED and the JOLTS to obtain the layoff series in figure 1. To extend the layoff series back in time before the advent of the JOLTS, they use the BED to construct synthetic, JOLTS-like layoff rates. Davis and others (2010) discuss sample design issues in the JOLTS and develop the adjustment methodology implemented by Davis and others (2012).

5. See Bartlesman and Doms (2000) and Foster, Haltiwanger, and Krizan (2001) for reviews of the evidence on reallocation and productivity growth. 
Figure 1. Four Measures of Job Loss, 1990-2011Q2a

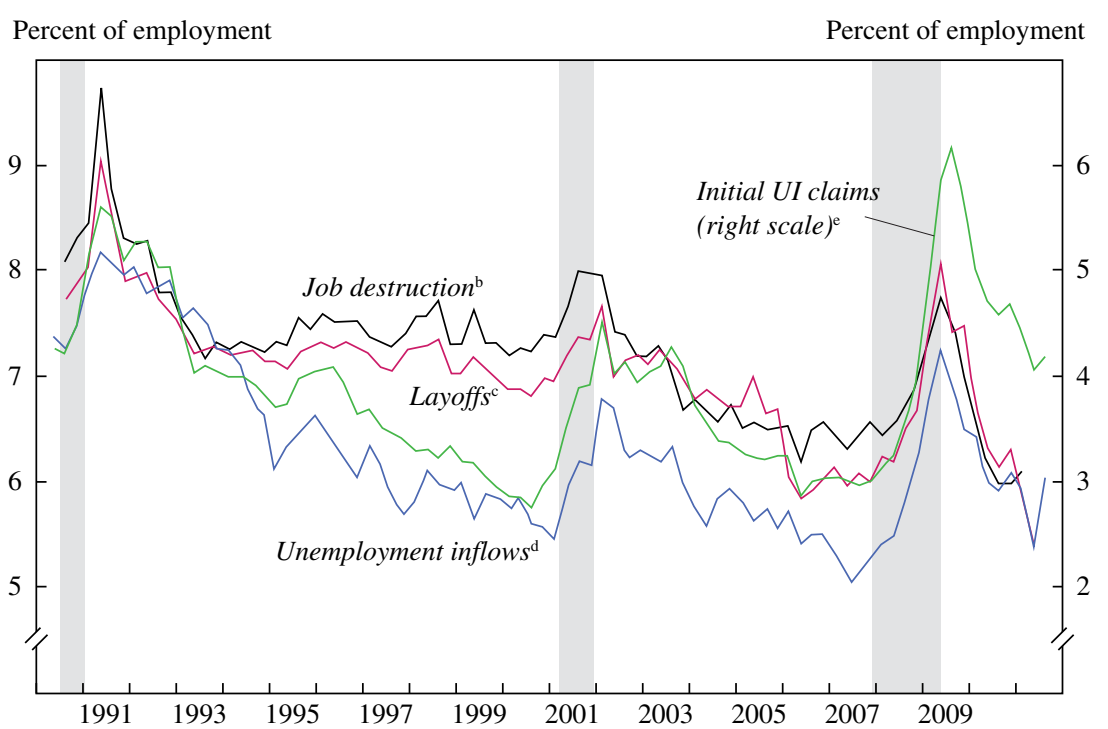

Sources: Bureau of Labor Statistics, Department of Labor, and Census Bureau data, Davis and others (2012), and authors' calculations.

a. All series are seasonally adjusted quarterly rates and are scaled to the left scale except where stated otherwise. Shaded areas indicate NBER-dated recessions.

b. Rates refer to the private sector only. They are tabulated directly from establishment-level data from the Business Employment Dynamics (BED) program by Davis and others (2012) for 1990Q2-2010Q2 and spliced to published BED statistics for 2010Q3 and 2010Q4. The splice is based on overlapping data from 2006 Q1 to 2010 Q2.

c. The JOLTS concept is used. Rates are constructed from JOLTS establishment-level data for 2001Q3-2010Q2 and extended back to 1990Q2 by Davis and others (2011); rates for 2010Q3-2011Q2 are constructed by summing monthly rates from the JOLTS and splicing to earlier years based on overlapping data from 2006Q1 to 2010Q2.

d. Monthly rates are calculated from CPS data as the number unemployed less than 5 weeks divided by total civilian employment, then summed over months. To adjust for the 1994 CPS redesign, we divide the number of short-term unemployed by 1.1 before 1994. See Polivka and Miller (1998) and Shimer (2007) on the CPS redesign.

e. The sum of weekly new claims is rescaled to represent $4 \frac{1 / 3}{3}$ weeks of claims, then divided by monthly nonfarm payroll employment from the Current Employment Statistics, then summed over months to quarterly rates. Weekly new claims data are available at www.ows.doleta.gov/unemploy/ claims.asp. 
the evidence on the costs associated with job displacement. That evidence focuses, quite deliberately, on the types of job loss events that often involve serious consequences for workers and their families.

Second, all four series in figure 1 exhibit strongly countercyclical movements, with clear spikes in the three recessions covered by our sample period. ${ }^{6}$ For example, the quarterly layoff rate rises by 129 basis points from 1990Q2 to 1991Q1, 85 basis points from 2000Q2 to 2001Q4, and 208 basis points from 2007Q3 to 2009Q1. Interestingly, each measure in figure 1 starts to rise before the onset of a recession (as dated by the National Bureau of Economic Research) and turns down before the resumption of an expansion. This pattern confirms the well-known usefulness of initial UI claims as a leading indicator for business cycles, and it suggests that other job loss indicators behave similarly in this respect. ${ }^{7}$

Much of our study examines the earnings losses of long-tenure male workers who lose jobs in large-scale layoff events. To quantify those losses, we follow individual workers over time using annual earnings records maintained by the Social Security Administration (SSA). Figure 2 plots an annual job displacement measure for men constructed from the SSA data and compares it with annual measures of job destruction and initial claims for unemployment insurance benefits. Here, we report displacement rates in the population of male employees 50 years or younger with at least 3 years of prior job tenure, excluding government workers and certain services industries not covered by the Social Security system throughout our full sample period. Also shown are annual series for two measures of job destruction from the Census Bureau's Business Dynamics Statistics (BDS) program and initial claims for UI benefits. ${ }^{8}$

We regard a worker as displaced in year $y$ if he separates from his employer in $y$ and the employer experiences a mass-layoff event in $y$. We

6. This pattern holds in earlier postwar U.S. recessions as well. See, for example, Blanchard and Diamond (1989), Davis and Haltiwanger (1990), Davis, Faberman, and Haltiwanger (2006), and Elsby, Michaels, and Solon (2009).

7. As an example, the Conference Board uses new claims for UI benefits in constructing its Leading Economic Index. See Conference Board, "Global Business Cycle Indicators," www.conference-board.org/data/bcicountry.cfm?cid=1.

8. Figure 2 cumulates weekly UI claims over 12 months, but the calculations otherwise follow the same approach as in figure 1. The BDS job destruction series are available at an annual frequency and extend further back in time than the BED-based job destruction series in figure 1, but they are not as timely. Because the BDS series reflect 12-month changes in establishment-level employment, they are not directly comparable to the BED-based job destruction series based on 3-month changes. 
Figure 2. Job Displacement, Job Destruction, and Initial Claims for Unemployment Insurance Benefits, 1977 to 2011

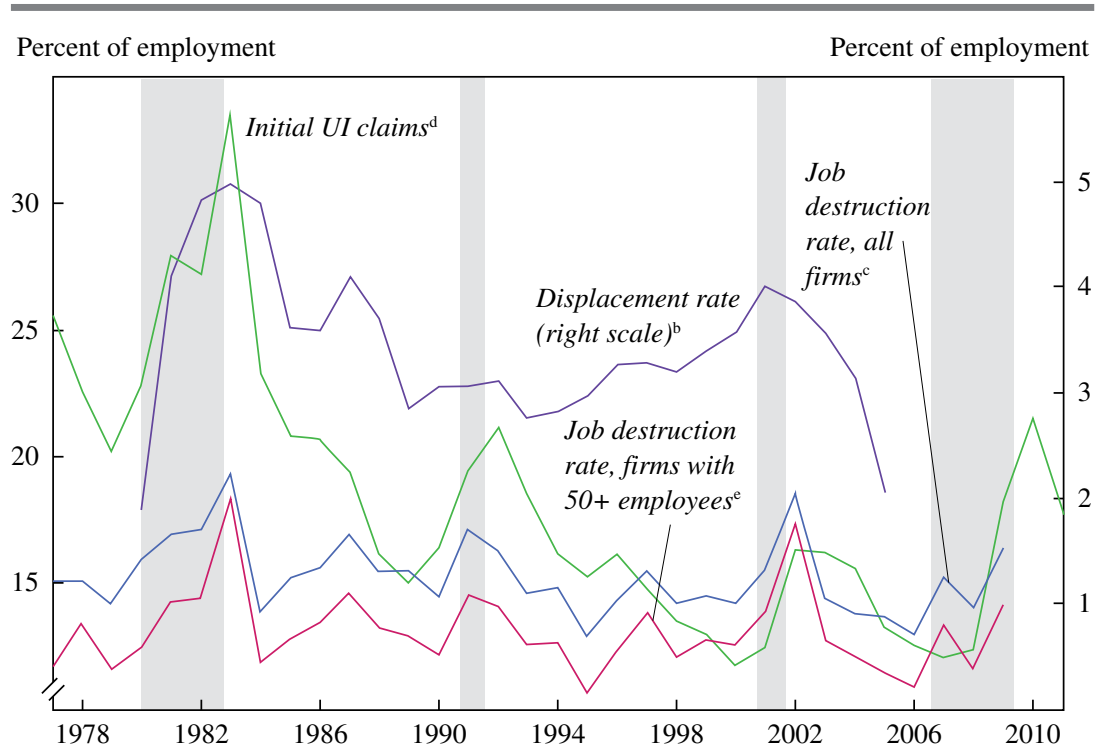

Sources: Social Security Administration, Bureau of Labor Statistics, Census Bureau, Department of Labor, Davis and others (2012), and authors' calculations.

a. All series are annual rates and are scaled to the left scale except where stated otherwise. Shaded areas indicate NBER-dated recessions.

b. Rates of job loss in mass-layoff events among male workers 50 years or younger with at least 3 years of prior job tenure, expressed as a percent of all male employees 50 or younger with at least 3 years of tenure at firms with at least 50 employees in the same age range. See text for a definition of mass-layoff events.

c. Rates for the nonfarm private sector are from the Business Dynamics Statistics program at the U.S. Census Bureau. They are tabulated from March-to-March employment changes summed over all contracting establishments in the Longitudinal Business Database. Available at www.ces.census.gov/ index.php/bds/bds_database_list.

d. Annual sums of weekly new claims as a percent of total employment; series is constructed as in figure 1 except that the monthly rates are summed from April of the previous year to March of the indicated year.

e. Rates for the nonfarm private sector from the Business Dynamics Statistics calculated from establishment-level employment changes at firms with at least 50 employees.

say a worker "separates" from an employer in year $y$ when he has earnings from the employer in $y-1$ but not in $y$. To meet the prior job tenure requirement, the worker must have positive earnings from the employer in question in $y-3, y-2$, and $y-1$. To qualify as a mass-layoff event in year $y$, the employer must meet the following criteria: 50 or more employees in $y-2$; employment contracts by 30 to 99 percent from $y-2$ to $y$; employment in $y-2$ is no more than 130 percent of employment in $y-3$; and 
employment in $y+1$ is less than 90 percent of employment in $y-2$. The 99 percent cutoff in the second condition ensures that we do not capture spurious firm deaths due to broken longitudinal links. The last two conditions exclude temporary fluctuations in firm-level employment. Although these criteria miss some displacements of long-tenure workers at larger employers, they help ensure that the separations we identify as job displacement events are indeed the result of permanent layoffs. ${ }^{9}$ To qualify as a job displacement event in $y$, we also require that the separation be from the worker's main job, defined as the one that accounts for the largest share of his earnings in $y-2$. For additional details on the data, sample, and measurement procedures, see von Wachter and others (2011).

To express job displacements in year $y$ as a rate in figure 2, we divide by the number of male workers 50 or younger in $y-2$ with at least 3 years of job tenure at firms with 50 or more employees in the industries covered by Social Security throughout our sample period. These workers make up 31 to 36 percent of all male workers 50 or younger in industries continuously covered by the SSA from 1980 to 2008 , depending on the year, 40 to 48 percent when we also restrict attention to those with 3 or more years of job tenure, and 70 to 74 percent when we further narrow the focus to firms with 50 or more employees.

The annual frequency of the measures in figure 2 somewhat obscures the timing of cyclical movements, but the broad patterns echo those in figure 1: job loss rates move in a countercyclical manner, and recessions involve notable jumps in job loss. The deep recession in the early 1980s saw dramatic increases in rates of job destruction and job displacement. For example, the annual job destruction rate at firms with 50 or more employees rose from 11.6 percent in 1979 to 18.3 percent in 1983. (To be clear, the latter figure reflects establishment-level employment contractions that occur from March 1982 to March 1983.) Our measure of the job displacement rate rose from 1.9 percent in 1980 to 5.0 percent in $1983 .{ }^{10}$ More generally,

9. Tabulations in Davis and others (2006) based on BED and JOLTS data indicate that most employment reductions are achieved through layoffs when firms contract by 30 percent or more.

10. The very high rates of initial UI claims in the early 1980s should be interpreted with caution. Temporary layoffs were a major phenomenon in the early 1980s, unlike in later recessions, and many temporarily laid-off workers qualified for UI benefits. Since few temporary layoff spells last more than a full year, and given that our definition of a mass layoff excludes temporary firm-level fluctuations, temporary layoffs play little role in our job displacement measure. For similar reasons, temporary layoffs have little impact on the annual job destruction measures. 
the job displacement rate is roughly 20 to 25 percent as large as annual job destruction rates, although it is worth stressing that the two measures pertain to different at-risk populations.

The incidence of job displacement might seem modest in any given year, but it cumulates to a large number during severe downturns. For example, summing the job displacement rates in figure 2 from 1980 to 1985 yields a cumulative displacement rate of more than 20 percent. ${ }^{11}$ This figure translates to about 2.7 million job displacement events over the 6-year period among men 50 years or younger with 3 or more years of job tenure and working in industries with continuous SSA coverage. This figure is conservative, given our restrictive criteria for mass-layoff events. According to the Displaced Worker Supplement to the CPS, 6.9 million persons with at least 3 years of prior tenure lost jobs due to layoffs from 2007 to 2009 (Bureau of Labor Statistics 2010). This figure includes women and does not impose our mass-layoff criteria. The Bureau of Labor Statistics also reports that an additional 8.5 million persons were displaced in 2007-09 from jobs held less than 3 years.

The top panel of figure 3 shows displacement rates for men with 3 to 5 years of job tenure and for men with 6 or more years. We impose the same requirements for age, firm size, industry coverage, and mass-layoff events as before. Displacement rates are considerably higher for workers with 3 to 5 years of tenure and more cyclically sensitive in the relatively shallow recessions and weak labor markets of the early 1990s and 2000s. These patterns conform to the view that workers with lower job tenure face greater exposure to negative firm-specific and aggregate shocks. The bottom panel shows displacement rates for men in three broad age groups. The basic pattern is clear: younger men tend to be more exposed to negative firm-specific and aggregate shocks that lead to job destruction.

Together, the two panels of figure 3 show that longer job tenure and greater labor market experience afford some insulation from the vicissitudes of firm-level employment fluctuations. However, it is well worth noting that tenure and experience provide less insulation in the deep aggregate downturn in the early 1980s. This aspect of figure 3 suggests that severe

11. In calculating the data for this figure, we allow the at-risk population to change from year to year. For some purposes it is more appropriate to consider the cumulative displacement rate for a fixed at-risk population. Consider, for example, the population of male workers younger than 50 with 3 or more years of job tenure at firms with at least 50 employees as of 1979, working in industries with continuous SSA coverage. By our criteria 16 percent of this fixed population experienced a job displacement event during 1980-85. 
Figure 3. Displacement Rates for Men, by Job Tenure and Age at Displacement, 1980 to $2005^{\text {a }}$

Percent

\section{By job tenure}

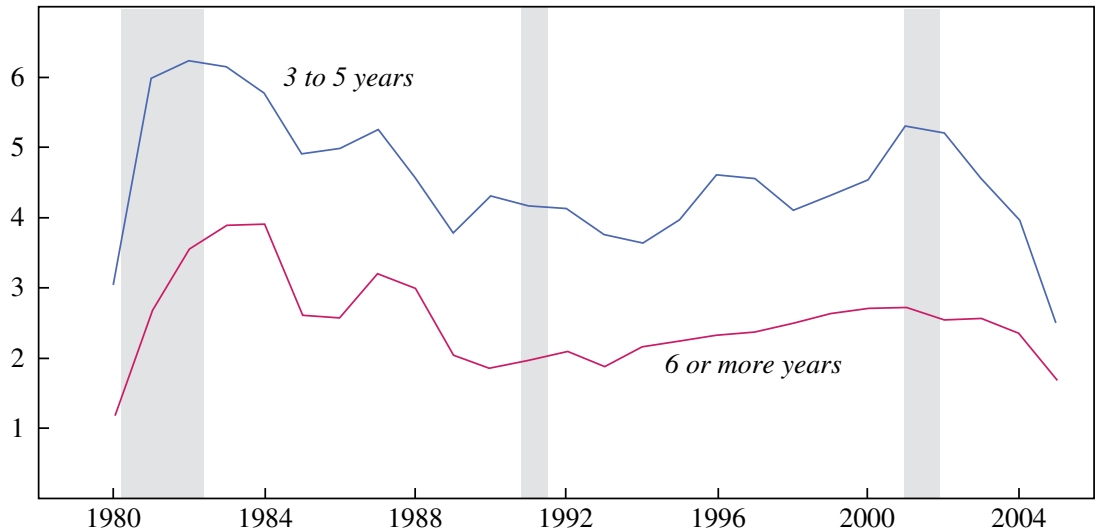

Percent

By age at displacement

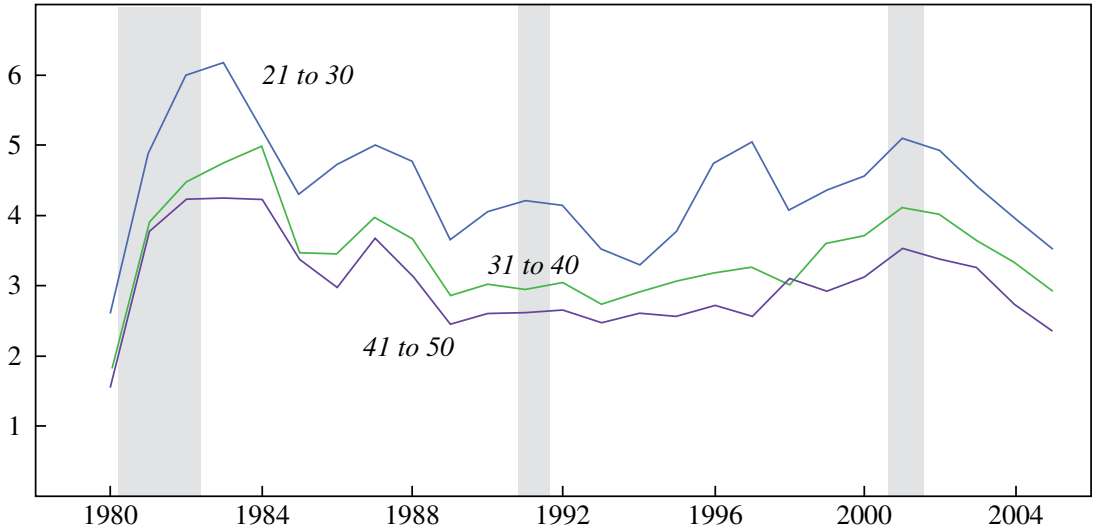

Sources: Authors' calculations using Social Security Administration data.

a. All series are annual rates. Both panels refer to men 50 or younger with at least 3 years of job tenure who lose jobs in mass-layoff events. Shaded bands indicate NBER-dated recessions. See text and figure 2 for full definitions and methods. 
recessions bite especially deeply into the distribution of valuable employment relationships. Evidence below on the cyclical behavior of the earnings losses associated with job loss supports this view as well.

\section{The Long-Term Earnings Effects of Job Displacement}

We turn now to evidence on the earnings losses associated with job displacement.

\section{II.A. Previous Research}

A growing body of research finds that job displacements often lead to large, persistent earnings losses. Most studies estimate the effect as the change in earnings from before to after the job loss relative to the contemporaneous earnings change of comparable workers who did not lose jobs. Studies differ somewhat in how they measure job loss and how they define the control group of nondisplaced workers.

Following earlier research, von Wachter and others (2011) define job displacement as the separation of a "stable" worker from his main employer during a period when the employer experiences a lasting employment decline of at least 30 percent. A stable worker is one with positive earnings at the firm in each of the three years immediately preceding the displacement event. Their definition also requires the employer to have at least 50 employees in the baseline period before the mass layoff. They exclude workers in two-digit industries not covered by SSA in the early 1980s, chiefly the public sector. Comparing the evolution of annual earnings for displaced workers with that of a control group of similar workers who did not separate in the displacement year or the next 2 years, von Wachter and others (2011) find that displacements in the early 1980 s led to average annual earnings losses relative to the control group of more than 30 percent of predisplacement annual earnings. Despite some recovery over time, even after 20 years the earnings of displaced workers remain 15 to 20 percent below the level implied by control group earnings.

The short- to medium-run effects of job displacement are larger in depressed areas and sectors. For example, using information on earnings and employers from UI records and a comparable definition of job displacement, Louis Jacobson, Robert Lalonde, and Daniel Sullivan (1993) find that job displacement in Pennsylvania in the early 1980s led on average to near-term earnings losses of more than 50 percent. Five years after displacement, the losses average 30 percent of predisplacement earnings, 
and they do not substantially fade even 10 years later (Sullivan and von Wachter 2009). Robert Schoeni and Michael Dardia (2003) and Yolanda Kodrzycki (2007) find similar results for job displacement in manufacturing industries in the mild recession of the early 1990s in California and Massachusetts, respectively.

Earnings losses are large and long lasting even in regions and periods with stronger labor markets. For example, Kenneth Couch and Dana Placzek (2010) examine job displacement using quarterly earnings data from UI records in Connecticut in the 1990s. They find that long-tenure workers suffer losses in earnings up to 5 years after a job displacement. Similarly, Jacobson and others (1993) show that workers displaced in Pennsylvania counties with below-average unemployment rates and above-average employment growth fare significantly better than the average displaced worker, but still suffer earnings losses. Von Wachter and others (2011) find substantial earnings losses for job displacements during the late-1980s expansion, losses that fade only after 15 years. Other studies (for example, Topel 1990, Ruhm 1991, and Stevens 1997) use longitudinal survey data to compare earnings of job losers with those of a control group. These studies typically do not focus on depressed areas or periods, but they also find large and persistent losses in earnings and wages.

The findings from administrative data pertain to annual or quarterly earnings. Hence, the earnings losses potentially arise from reductions in both employment and wages. However, the earnings loss for the median worker in the sample is about as large as, and more persistent than, the mean loss (von Wachter and others 2011, Schoeni and Dardia 2003). This result and survey-based evidence that most job losers return to employment (for example, Farber 1999) suggest that the bulk of earnings losses after job displacement reflects reductions in wage rates or hours worked.

One natural question about studies based on administrative data is how the earnings loss results depend on the definition of job displacement, the choice of control groups, and the specification of mass-layoff events. Von Wachter and others (2011) find that their results survive the use of alternative firm size thresholds, different definitions of mass layoffs, alternative employment stability requirements for control groups, and other robustness checks. Von Wachter, Elizabeth Handwerker, and Andrew Hildreth (2008) obtain similar results using control groups constructed from workers in similar firms and industries. Studies based on panel survey data that do not impose restrictions on firm size or firm events yield results for earnings similar to results based on administrative data (for example, Topel 1990, Ruhm 1991, Stevens 1997). 
Overall, a central finding in previous research is that job displacement leads to large and long-lasting earnings losses, especially under weak labor market conditions. This observation suggests that workers who have experienced job displacement events since 2008 are likely to suffer unusually severe and persistent earnings losses. Direct evidence on the losses of recently displaced workers is limited, however, in part because of lags in processing and analyzing administrative data sources. The latest Displaced Worker Supplement (DWS) to the CPS, conducted in January 2010 , contains recall data for workers displaced during 2007-09. Given the absence of a control group, the inability to incorporate earnings losses due to employment reductions, and the presence of measurement error in wages and job loss events, the DWS data tend to show smaller earnings losses than studies based on administrative data (von Wachter and others 2008). However, even the DWS data imply substantial earnings losses for persons who lost jobs during 2007-09. On the basis of the DWS data, the Bureau of Labor Statistics (2010) reports that only 49 percent of workers with 3 or more years of job tenure who were displaced during 2007-09 were employed as of January 2010, and that among the reemployed, 36 percent reported current earnings at least 20 percent lower than on the previous job.

The earnings losses associated with job displacement are large and persistent for both women and men and in all major industries. Older workers tend to have larger immediate losses than younger workers. Relative to a control group of nondisplaced workers of similar age, however, the losses of younger displaced workers are nonnegligible and persist over 20 years (von Wachter and others 2011). Earnings losses tend to rise with tenure on the job, industry, or occupation (for example, Kletzer 1989, Neal 1995, Poletaev and Robinson 2008). Yet losses for workers with 3 to 5 years of job tenure are substantial and long lasting, and even workers with less than 3 years of job tenure experience nonnegligible declines in annual earnings following a job displacement event (von Wachter and others 2011).

\section{II.B. Estimated Earnings Losses Associated with Job Displacement}

We now follow von Wachter and others (2011) in estimating the earnings effects of job displacement and their sensitivity to economic conditions at the time of displacement. We define job displacement as in section I as the separation of long-tenure men, 50 years or younger, in mass-layoff events at firms with at least 50 employees at baseline. We also provide some results for women and for older men. To estimate the effects of job displacement, we compare the earnings path of workers who experience 
job displacement with the earnings path of similar workers who did not separate during the same time period, while controlling for individual fixed effects and differential earnings trends.

We implement this comparison by estimating the following distributedlag model separately for each displacement year $y$ from 1980 onward:

$$
e_{i t}^{y}=\alpha_{i}^{y}+\gamma_{t}^{y}+\bar{e}_{i}^{y} \lambda_{t}^{y}+\beta^{y} X_{i t}+\sum_{k=-6}^{20} \delta_{k}^{y} D_{i t}^{k}+u_{i t}^{y},
$$

where the outcome variable $e_{i t}^{y}$ is real annual earnings of individual $i$ in year $t$ in 2000 dollars (deflated using the consumer price index), $\alpha_{i}^{y}$ are coefficients on worker fixed effects, $\gamma_{t}^{y}$ are coefficients on calendar-year fixed effects, $X_{i t}$ is a quartic polynomial in the age of worker $i$ at year $t$, and the error $u_{i t}^{y}$ represents random factors. To allow further differences in annual earnings increments by a worker's initial level of earnings, the specification includes differential year effects that vary proportionally to the worker's predisplacement average earnings, $\overline{\boldsymbol{e}}_{i}^{y}$, calculated using the years $y-5$ to $y-1$. The $D_{i t}^{k}$ are dummy variables equal to 1 in the worker's $k$ th year before or after his displacement, and zero otherwise, where $k=1$ denotes the displacement year and $k=0$ denotes the final year of earnings with the predisplacement employer. In the 1985 displacement-year regression, for example, $D_{i t}^{5}=1$ for $t=1989$ and zero otherwise for a worker $i$ who experiences displacement in 1985 by our criteria.

We estimate equation 1 by displacement year using annual, individuallevel observations in the SSA data from 1974 to 2008. To construct our regression sample for displacement year $y$, we start with a 1 percent sample of men with a valid Social Security number in $y$. We then keep those that had positive Social Security earnings in $y$ and impose the same restrictions with respect to firm size, industry, worker age, and job tenure as in figure 2. We then select data on workers displaced in $y, y+1$, and $y+2$ plus data on workers in a control group described below. ${ }^{12}$ For the control group workers in a given displacement-year sample, we set $D_{i t}^{k}=0$ for all $t$. Although we consider displacement events through age 50, we use earnings data through age 55. We follow the same approach for women in all respects but analyze their earnings outcomes separately.

12. We include displacements that occur in $y+1$ and $y+2$ in the sample for displacement year $y$ to raise the number of observations of displaced workers, and to align the inclusion windows for displaced and control group workers. Note that this approach smooths the estimated earnings effects of job displacement from one displacement year to the next, which works against finding differences between recessions and expansions. 
The earnings data for the control group help identify the year effects $\gamma_{i}^{y}$ and $\lambda_{t}^{y}$. Given the presence of the year effects and worker fixed effects in equation 1 , the coefficients $\delta_{k}^{y}$ on the dummies $D_{i t}^{k}$ measure the time path of earnings changes for job separators from 6 years before and up to 20 years after a displacement, relative to the baseline and relative to the change in earnings of the control group. ${ }^{13}$ The baseline consists of years 7 and 8 before displacement. ${ }^{14}$ To interpret the estimated $\delta_{k}^{y}$ coefficients as the earnings effect of job displacement requires that, conditional on worker fixed effects and the other control variables, the control group earnings capture the counterfactual earnings of displaced workers in the absence of job displacement. Mechanically, to obtain the counterfactual earnings path of a displaced worker $i$ absent displacement, we evaluate equation 1 at $D_{i t}^{k}=0$ for all $k$.

For the displacement-year $y$ regression sample, the control group consists of workers not separating in $y, y+1$, and $y+2$ ("nonseparators"). Hence, as is typical in the literature on job displacement based on administrative data, we exclude so-called non-mass-layoff separators from $y$ to $y+2$ from the control group. Non-mass-layoff separators are workers who quit their jobs or were laid off by firms with an employment drop of less than 30 percent. We impose the same restrictions with respect to firm size, industry, worker age, job tenure, and sex as for displaced workers. We discuss the impact of alternative control groups and concerns related to potential selection bias in the earnings loss estimates in section II.D.

Figure 4 reports results for men 50 or younger with at least 3 years of job tenure as of the displacement year. The top panel shows the average time paths of mean raw earnings before and after displacement for workers displaced in recessions and expansions. If a peak or a trough falls within a given calendar year, we weight the year according to the number of its months in expansion or recession when computing the averages. The middle panel shows the average earnings loss profiles for workers displaced in recessions and in expansions, relative to the control group, and normalized to reflect changes relative to mean earnings in years $t-4$ to $t-1$ before displacement. To obtain average earnings losses for job displacements

13. Since our sample window stops in 2008 , for displacement years after 1988 we do not observe 20 years of earnings data after a displacement. For these years, the postdisplacement dummies are included up to the maximum possible number of years.

14. For 1980 the baseline is years 5 and 6 before displacement, and for 1981 it is years 6 and 7 before displacement. We also drop the dummy variable for the first calendar year in each regression. These zero restrictions, two for the baseline and one for the first calendar year, resolve the potential collinearity among the dummy variables in equation 1 . 
in expansions and recessions, we average over estimated values of $\delta_{k}^{y}$ in recession and expansion years, respectively. The bottom panel shows these losses as a fraction of predisplacement mean earnings.

The bottom panel of figure 4 shows that the earnings losses of displaced workers relative to the control group are very large initially: 39 percent of predisplacement earnings in the first year for displacements that occur in recessions and 25 percent for displacements that occur in expansions. They are also long lasting, ranging from 15 to 20 percent from 10 to 20 years out for displacements that occur in recessions and about 10 percent for those that occur in expansions. These estimates are robust to many alternative specifications, as discussed below and in von Wachter and others (2011). For example, the earnings losses are similar if one defines a mass-layoff event as a firm-level employment decline of at least 80 percent rather than 30 percent. They are slightly larger for workers with 6 years or more of job tenure, the main comparison group of Jacobson and others (1993), and slightly smaller for workers with 3 to 5 years of job tenure.

Figure 5 plots estimated short-term earnings losses against the national unemployment rate in the year of displacement. We define the short-term earnings loss as the loss in year $t+2$ for a job displacement in $t$, as estimated from equation 1 , divided by predisplacement mean earnings in years $t-4$ to $t-1$. The figure displays a clear inverse relationship. Regressing the earnings loss on the unemployment rate at displacement yields an $R^{2}$ of 0.22 and a slope coefficient of -0.022 (with a standard error of 0.008 ). That is, a rise in the unemployment rate from 5 percent to 9 percent at the time of displacement implies that the earnings loss in the third year of displacement increases from 18 percent to 26 percent of average annual predisplacement earnings. Since the earnings recovery pattern in the bottom panel of figure 4 is approximately parallel in expansions and recessions, figure 5 suggests that the state of the labor market at displacement sets the initial level of losses, from which a gradual recovery ensues. We will use this result when calculating present-value earnings losses in the next subsection.

\section{II.C. Present-Value Earnings Losses Associated with Job Displacement}

Figures 4 and 5 point to large short-term and long-term earnings losses associated with job displacement and large earnings loss differences between displacements that occur in expansions and those that occur in recessions. To estimate the present discounted value (PDV) of the annual earnings losses summarized in figure 4 , we proceed as follows. Using a real interest rate of 5 percent, we sum the discounted losses over a 20-year 
Figure 4. Earnings of Displaced Male Workers before and after Displacement ${ }^{\mathrm{a}}$

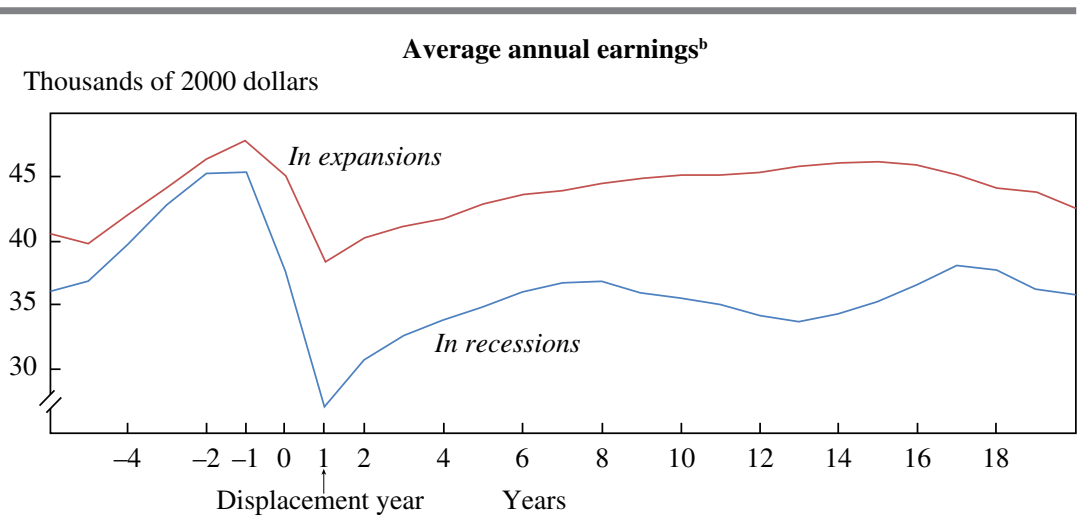

Average earnings loss relative to control group earnings ${ }^{c}$

Thousands of 2000 dollars
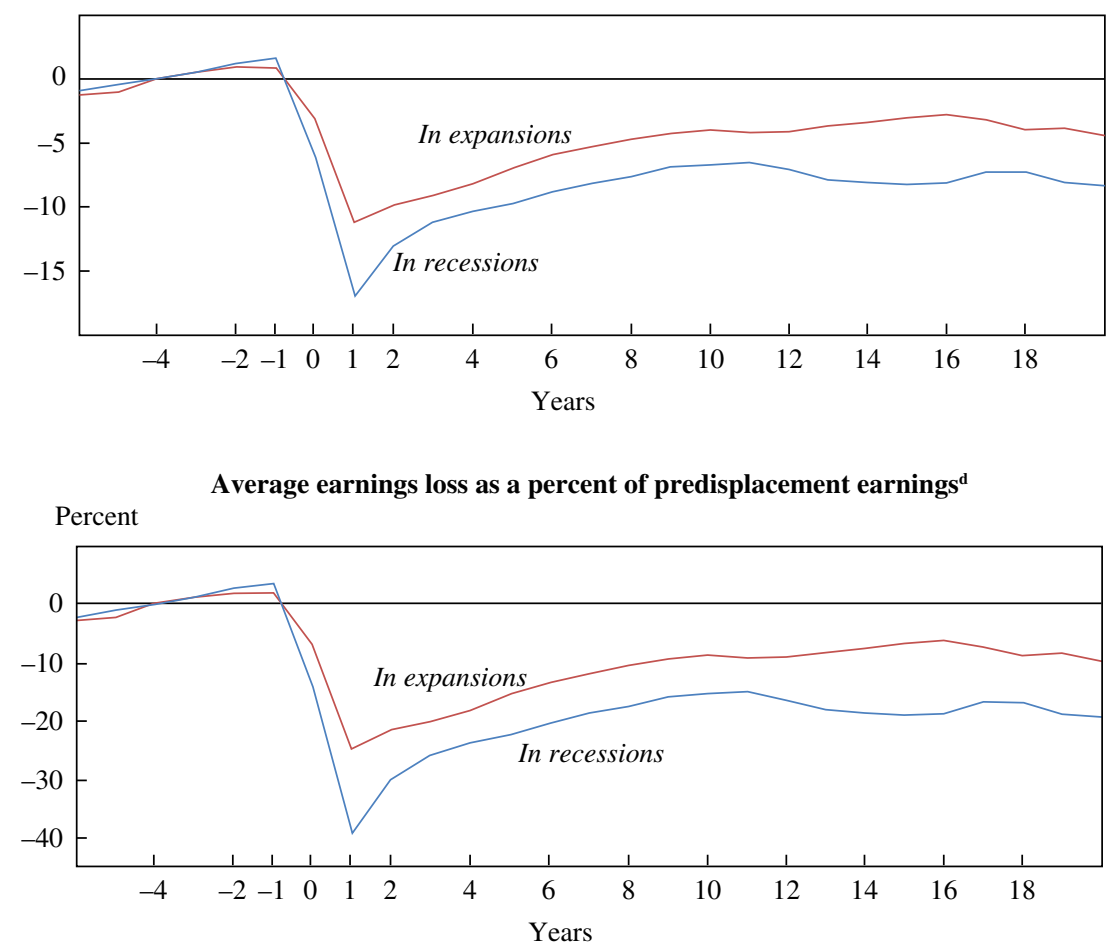

(continued) 
Notes to figure 4:

Source: Authors' calculations.

a. In each panel the curve labeled "In recessions" shows average outcomes for workers displaced in recession years from 1980 to 2005, and the curve labeled "In expansions" shows average outcomes for those displaced in expansion years in that period. When a given displacement year straddles recession and expansion periods, that year's values are apportioned according to the number of months in each period (see the text for further details). Displaced workers are men 50 or younger who separate from their main job in a mass-layoff event and who have at least 3 years of prior job tenure. All averages are estimated using administrative data on W-2 earnings (following von Wachter and others 2011) and include observations with zero earnings.

b. Mean annual raw earnings before and after displacement of workers displaced in recessions and of those displaced in expansions.

c. Average earnings losses of displaced workers, as estimated from displacement-year regression models of annual earnings for displaced workers and control group workers. The regression models include controls for worker effects, a quartic polynomial in age, calendar-year effects, and an interaction of the latter with individual average earnings in the 5 years preceding displacement. See equation 1 and the accompanying discussion for further details.

d. Earnings losses in the middle panel expressed as a percent of displaced workers' average annual earnings in the predisplacement baseline period.

\section{Figure 5. Earnings Losses of Men in the Third Year of Displacement versus Unemployment Rate in the Displacement Year, 1980-2005}

Earnings $\operatorname{loss}^{\mathrm{b}}$ (fraction of predisplacement earnings)

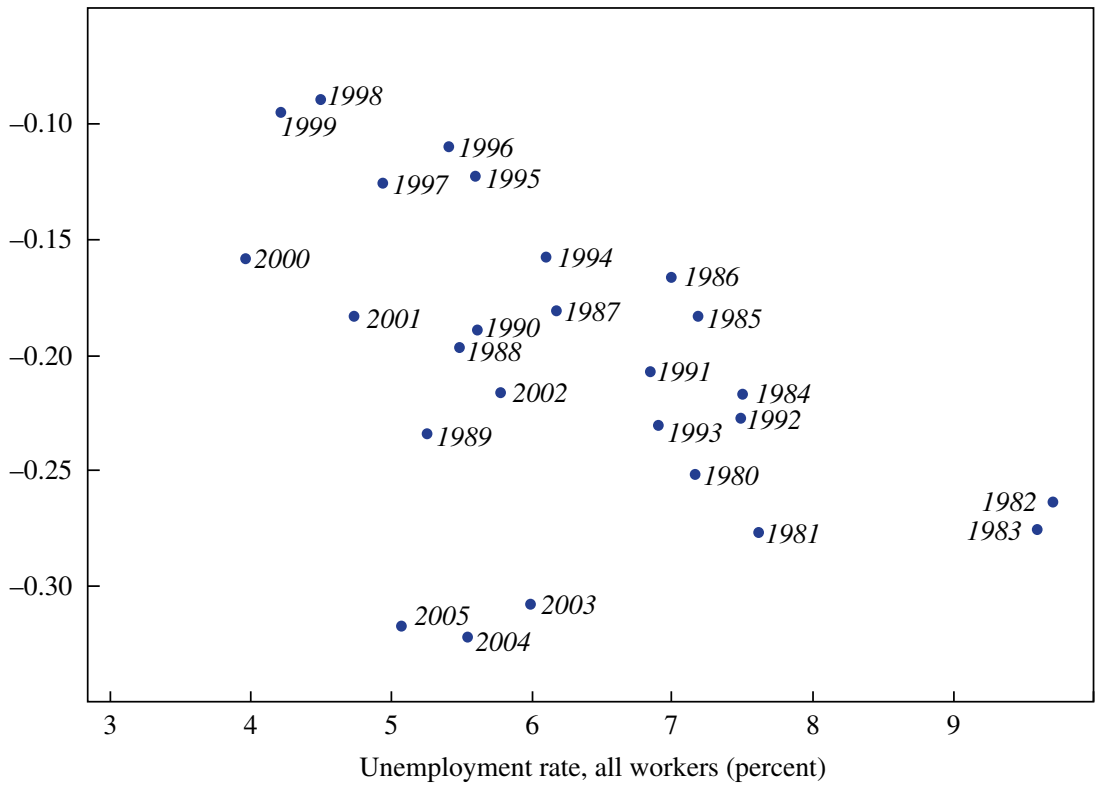

Source: Social Security Administration data, Bureau of Labor Statistics data, and authors' calculations. a. Year labels indicate year of displacement; unemployment rate is that of the same year.

b. Average earnings loss (including observations with zero earnings) in the third year of displacement (year 3) for men 50 or younger with 3 or more years of prior job tenure, expressed as a fraction of average annual earnings in the years -4 to -1 before displacement in year 1 . Losses are calculated from the administrative earnings data (W-2 earnings records) used in von Wachter and others (2011) and described in the text. 
period starting with the year of displacement. Since we do not observe the full 20 years of earnings after a job displacement for workers displaced in later years, we impose a common rate of decay past the 10th year. Hence, the estimated mean PDV earnings losses for displacements that occur in, say, a recession are

$$
P D V_{\mathrm{Loss}}^{R}=\sum_{s=1}^{10} \bar{\delta}_{s}^{R} \frac{1}{(1+r)^{s-1}}+\sum_{s=11}^{20} \bar{\delta}_{10}^{R} \frac{(1-\bar{\lambda})^{s-10}}{(1+r)^{s-1}},
$$

where $\bar{\delta}_{s}^{R}$ is the average estimated earnings loss in year $s$ after displacement (derived by averaging equation 1 estimates over displacement-year regressions), and $\bar{\delta}_{10}^{R}(1-\bar{\lambda})^{s-10}$ is an extrapolated earnings loss using the common decay rate $\bar{\lambda}$. The evolution of earnings losses is roughly parallel for displacements in expansions and recessions, so we use the average decay rate of earnings losses from years 11 to 20 after displacement, estimated using data for all available workers and years. ${ }^{15}$

Other approaches are possible. Rather than a common decay rate, we could use estimated earnings losses for the largest available sample of years and workers for each value of $s$ up to $s=20$. That approach, however, involves a different mix of years for each value of $s$, and for large values of $s$ the sample would be dominated by displacement events in the 1980s. Moreover, as the sample of workers displaced in a given year ages and their labor force participation declines, the estimates for long after the displacement year may be affected by changes in composition and greater sampling error in the increasingly smaller samples. Similarly, using actual estimates for the long-run follow-up period may put weight on cohorts that experience particularly long-lasting effects. Given our aim to approximate the average PDV loss for a typical worker in boom years and in recession years, we choose a common decay rate for all displacement cohorts. To smooth out sampling variability in the recovery pattern and to maximize the number of available cohorts, we calculate the decay rate as the average of annualized log differences in earnings losses from years 6 to 10 to years 11 to 15 after displacement. This approach balances the influence of displacements in the early 1990s, which reflect a strong recovery in the high-pressure labor market of the mid- to late 1990s, with the influence of displacements in other periods.

15. If the out-year earnings recovery is faster for displacements that occur in booms, this choice understates the cyclical differences in the cost of job loss. 
Since earnings levels change over time and may differ between displacements that occur in expansions and those that occur in recessions, we consider two ways of normalizing the absolute earnings losses. First, we scale the PDV earnings loss by displaced workers' mean annual earnings in years $t-4$ through $t-1$ before displacement. This approach expresses the loss as the number of earnings years lost at the previous level of earnings. Second, we express the PDV earnings loss as a percentage of PDV earnings along a counterfactual earnings path in the absence of displacement. To do so, we first construct the counterfactual by adding the absolute value of the estimated earnings loss (middle panel of figure 4) back to the actual level of average earnings (top panel of figure 4). In the notation of equation 1 , for workers displaced in year $y$, we thereby effectively obtain $\bar{e}_{t}^{c f, y}=\bar{\alpha}_{i}^{y}+\gamma_{t}^{y} \bar{e}_{i}^{y} \lambda_{t}^{y}+\beta^{y} \bar{X}_{t}^{y}$. Using the mean earnings of displaced workers as a benchmark ensures that we average over the right worker fixed effects and obtain the right earnings levels. We then take the average of the counterfactual in years belonging to recessions and the average in years belonging to expansions. ${ }^{16}$ Using these averages, we divide the PDV earnings loss by the resulting PDV of counterfactual earnings in booms and recession, respectively.

Table 1 reports these alternative measures of the PDV earnings loss after a job displacement, again for men 50 years or younger with at least 3 years of positive earnings at an employer with at least 50 workers. The definition of displacement is the same as in figure 4. The first row shows estimated PDV earnings losses, averaged over all displacement years, of $\$ 77,557$ in dollars of 2000 . This amounts to 1.71 years of average predisplacement earnings and 11.9 percent of the PDV of counterfactual earnings. The next two rows show our measures of PDV earnings losses separately for expansions and recessions. As anticipated from figure 4, job displacements lead to very large declines in PDV earnings, and the losses are much larger for displacements occurring in recessions. The average worker displaced in a recession experiences PDV losses of $\$ 109,567$, equivalent to 2.50 years of average predisplacement earnings, and an 18.6 percent loss relative to counterfactual earnings. In contrast, the PDV earnings loss experienced by workers displaced in an expansion averages $\$ 72,487$, which amounts to 1.59 years of predisplacement earnings and an 11.0 percent shortfall relative to the counterfactual.

16. Similarly, we calculate the corresponding mean of actual annual earnings before and after displacement by first obtaining the average for each displacement year, $\bar{e}_{t}^{\text {act., } y}$, and then averaging over the years belonging to expansions and recessions. 
Table 1. Present-Value Earnings Losses after Mass-Layoff Events, Men 50 or Younger with at Least 3 Years Prior Job Tenure, 1980-2005a

\begin{tabular}{|c|c|c|c|c|}
\hline \multirow[b]{2}{*}{ Subgroup ${ }^{\mathrm{b}}$} & \multirow[b]{2}{*}{$\begin{array}{c}\% \text { of all } \\
\text { years from } \\
1980 \text { to } 2005\end{array}$} & \multicolumn{3}{|c|}{ PDV of average loss at displacement } \\
\hline & & Dollars & $\begin{array}{l}\text { As a multiple of } \\
\text { predisplacement } \\
\text { annual earnings }\end{array}$ & $\begin{array}{c}\text { As \% of PDV of } \\
\text { counterfactual } \\
\text { earnings }{ }^{\mathrm{c}}\end{array}$ \\
\hline All & 100 & 77,557 & 1.71 & 11.9 \\
\hline $\begin{array}{l}\text { Displaced in } \\
\text { expansion year }\end{array}$ & 88 & 72,487 & 1.59 & 11.0 \\
\hline $\begin{array}{l}\text { Displaced in } \\
\text { recession year }\end{array}$ & 12 & 109,567 & 2.50 & 18.6 \\
\hline \multicolumn{5}{|l|}{$\begin{array}{l}\text { Displaced in year with } \\
\text { unemployment rate: }\end{array}$} \\
\hline$<5.0 \%$ & 23 & 50,953 & 1.06 & 9.9 \\
\hline $5.0-5.9 \%$ & 35 & 71,460 & 1.56 & 10.9 \\
\hline $6.0-6.9 \%$ & 13 & 71,006 & 1.58 & 10.7 \\
\hline $7.0-7.9 \%$ & 21 & 89,792 & 2.07 & 14.4 \\
\hline$\geq 8.0 \%$ & 8 & 121,982 & 2.82 & 19.8 \\
\hline
\end{tabular}

Source: Authors' calculations using equation 2 and estimates from equation 1.

a. PDVs are calculated over 20 years of job displacement at an annual discount rate of 5 percent. Masslayoff events are defined as in section I. See text for further description. Dollar figures are in dollars of 2000.

b. When a year contains both expansion and recession months or monthly unemployment rates that fall in different ranges, that year's values are allocated proportionally to the number of months in each cyclical state or range.

c. Counterfactual earnings are what the displaced worker would have earned over the same 20 years had he not been displaced.

Recall from figure 1 that the incidence of job displacement is also much greater in recessions. Given that displacements have more severe consequences in recessions, the unweighted averages over years in the first row of table 1 effectively give less weight to persons displaced in recessions, and thus understate average PDV earnings losses taken over all displaced workers. Similarly, because we weight all recession years equally, and recessions with higher displacement rates also involve higher earnings losses, table 1 understates the average PDV earnings losses for job displacements that occur in recessions.

The last five rows of table 1 show how estimated PDV earnings losses vary with the unemployment rate in the year of displacement. The unemployment rate reflects contemporaneous labor market conditions in a different way than business cycle dating. As before, to calculate the table entries, we first estimate PDV earnings losses by year of displacement. We then average over all years falling into an indicated unemployment range, assigning fractional weights to years that fall partly into a given range. The results show that PDV earnings losses rise steeply with the unemployment 
rate in the year of job displacement. This important finding strongly reinforces and extends the evidence in figure 5.

To take this result one step further, we repeat our procedure for calculating PDV earnings losses by year of displacement. We now depart from working with averages over multiple displacement years and consider a separate earnings loss path for each displacement year. When we have more than 10 years of postdisplacement information, we use the first 10 years and extrapolate from year 11 to year 20 using the same average rate of decay as before. When we have less than 10 years of postdisplacement information (that is, starting in 1999), we also use the available information for other years to construct decay rates in the earlier postdisplacement years. For displacement years with less than 10 but more than 5 years of postdisplacement data, we set the decay rate to the annualized log difference of losses between the 6th and the 10th year after displacement, taken from displacement years for which this information is available. For those years with less than 6 displacement years, we use the annualized log differences of losses between the $2 \mathrm{nd}$ and the 5 th displacement year. For years closer to the end of our sample period, we necessarily rely more heavily on extrapolation.

Figure 6 plots the resulting PDV earnings losses (expressed as multiples of average annual predisplacement earnings) against the unemployment rate in the year of displacement. The figure again shows an approximately linear relationship, which is not surprising given the roughly linear relationship in figure 5 and our use of a common decay rate beyond the 10th year after displacement. Even allowing for different postdisplacement recovery patterns, the figure suggests that PDV earnings losses increase approximately linearly with the unemployment rate in the year of displacement. A linear regression of the PDV loss measure on the unemployment rate at displacement yields an $R^{2}$ of 0.27 with a slope coefficient of -0.23 (standard error of 0.08). Thus, an increase in the unemployment rate at displacement from 5 percent to 9 percent implies that PDV earnings losses rise from 1.6 years to 2.5 years of predisplacement earnings. When we add an indicator for recession years to this descriptive regression model, it is not statistically significant.

Table 2 shows PDV earnings losses for displaced women and for various age and tenure subgroups of displaced men. ${ }^{17}$ The PDV earnings losses due to job displacement are large for all these groups. They are smaller for

17. The online appendix, accessible on the Brookings Papers web site, www.brookings. edu/economics/bpea.aspx, under "Past Editions," contains additional results by age group. 
Figure 6. Cumulative Earnings Losses after Displacement versus Unemployment Rate in the Displacement Year, 1980-2005

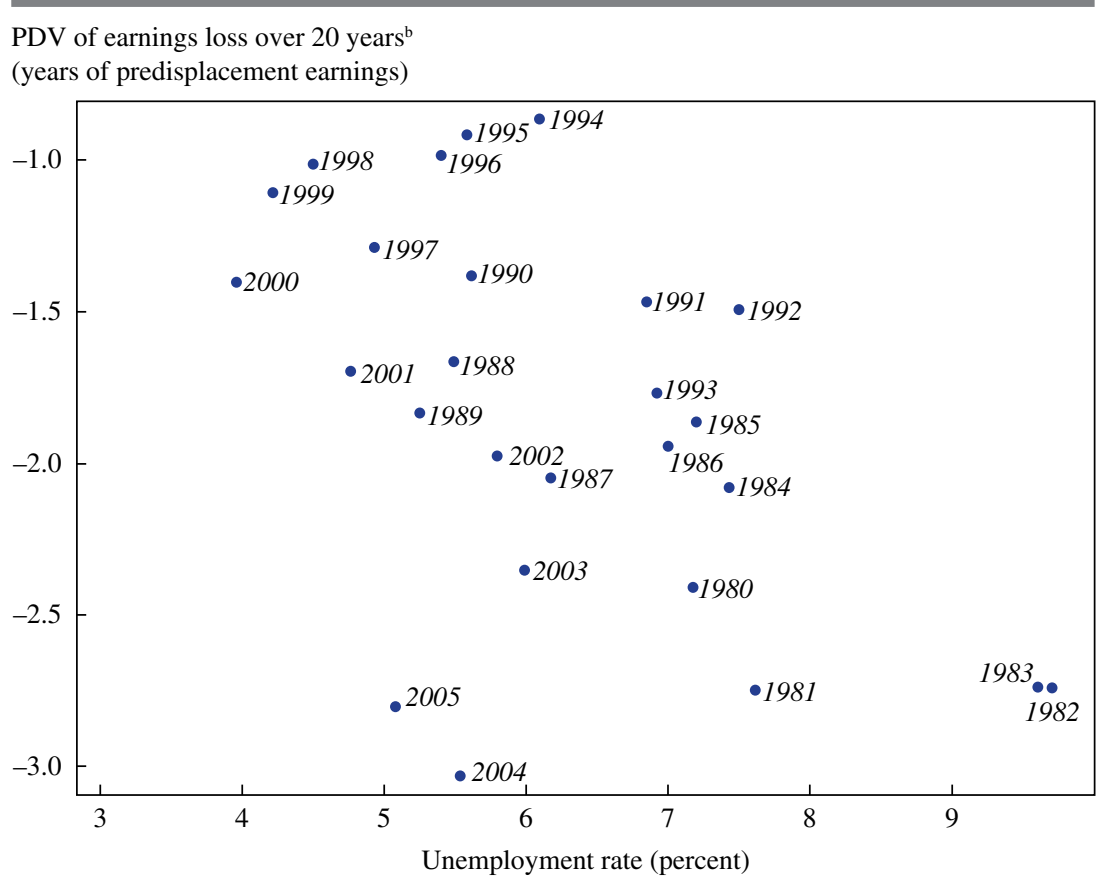

Source: Social Security Administration data, Bureau of Labor Statistics data, and authors' calculations.

a. Year labels indicate year of displacement; unemployment rate is that of the same year.

b. We calculate present-value earnings losses, following equation 2 in the text, over a 20 -year horizon using a 5 percent annual discount rate.

women than for men, but not dramatically so in the last two columns, which effectively control for differences in average earnings levels between men and women. For example, the average losses for women amount to 1.5 years of predisplacement earnings (table 2), compared with 1.7 years for the corresponding group of men (table 1). Comparison of tables 1 and 2 also shows that the losses are larger for men with longer job tenure before displacement. The panels reporting results for male age subgroups show that, except for men displaced near the end of their working lives, PDV earnings losses are much larger for displacements that occur in recessions.

\section{II.D. On Selection Bias and Sensitivity to Control Group Choice}

We now discuss two potential concerns about the earnings loss estimates that underlie our results in figures 4 to 6 and tables 1 and 2, namely, 
Table 2. Present-Value Earnings Losses after Mass-Layoff Events, Various Groups, $1980-2005^{\mathrm{a}}$

\begin{tabular}{|c|c|c|c|}
\hline \multirow[b]{2}{*}{ Group $^{\mathrm{b}}$} & \multicolumn{3}{|c|}{ PDV of average loss at displacement } \\
\hline & Dollars & $\begin{array}{l}\text { As a multiple of } \\
\text { predisplacement } \\
\text { annual earnings }\end{array}$ & $\begin{array}{c}\text { As } \% \text { of PDV of } \\
\text { counterfactual } \\
\text { earnings }\end{array}$ \\
\hline \multicolumn{4}{|c|}{ Women $21-50,3$ or more years tenure } \\
\hline All years & 38,033 & 1.5 & 10.9 \\
\hline Expansion years only & 33,164 & 1.3 & 9.5 \\
\hline Recession years only & 68,782 & 3.3 & 20.6 \\
\hline \multicolumn{4}{|c|}{ Men $21-50,6$ or more years tenure } \\
\hline All years & 106,900 & 2.0 & 12.9 \\
\hline Expansion years only & 100,543 & 1.8 & 11.9 \\
\hline Recession years only & 148,400 & 3.0 & 20.0 \\
\hline \multicolumn{4}{|c|}{ Men $21-30,3$ or more years tenure } \\
\hline All years & 50,240 & 2.1 & 9.8 \\
\hline Expansion years only & 39,639 & 1.7 & 7.8 \\
\hline Recession years only & 117,322 & 4.0 & 22.0 \\
\hline \multicolumn{4}{|c|}{ Men $31-40,3$ or more years tenure } \\
\hline All years & 49,599 & 1.2 & 7.7 \\
\hline Expansion years only & 42,555 & 1.0 & 6.5 \\
\hline Recession years only & 93,833 & 2.2 & 16.0 \\
\hline \multicolumn{4}{|c|}{ Men $41-50,3$ or more years tenure ${ }^{d}$} \\
\hline All years & 98,519 & 1.8 & 15.9 \\
\hline Expansion years only & 95,716 & 1.7 & 15.1 \\
\hline Recession years only & 116,515 & 2.2 & 21.9 \\
\hline \multicolumn{4}{|c|}{ Men $51-60,3$ or more years tenure } \\
\hline All years & 99,288 & 1.8 & 24.0 \\
\hline Expansion years only & 97,934 & 1.7 & 23.1 \\
\hline Recession years only & 108,248 & 2.1 & 31.1 \\
\hline
\end{tabular}

Source: Authors' calculations using equation 2 and estimates from equation 1.

a. PDVs are calculated over the 20 years following displacement as described in table 1 , except as noted below. Dollar figures are in dollars of 2000.

b. Ages and years of tenure are as of time of displacement. Values for years containing both expansion and recession months or monthly unemployment rates that fall in different ranges are calculated as described in table 1 .

c. Counterfactual earnings are what the displaced worker would have earned over the same 20 years had he or she not been displaced.

d. PDVs are calculated over 15 years.

e. PDVs are calculated over 10 years. 
selection bias and the sensitivity of our results to the choice of control group. Relative to nonseparators (our control group), non-mass-layoff separators experience earnings losses that are smaller and less persistent than the losses experienced by mass-layoff separators. Thus, if we include non-mass-layoff separators in the control group, the estimated earnings losses due to job displacement become smaller. Von Wachter and others (2011) estimate a version of equation 1 with non-mass-layoff separators as part of the control group. This change in the composition of the control group reduces the estimated earnings losses by about one-quarter. Von Wachter and others also consider instrumental variables estimates that are not affected by the presence of voluntary separators, which we discuss below, and obtain results very similar to those reported here. After considering various estimators, they confirm the conclusion from previous research that the "true" loss at displacement is closer to the estimates that exclude non-mass-layoff separators from the control group.

Estimates based on equation 1 may overstate earnings losses at displacement because displaced workers are negatively selected on observable and unobservable characteristics with respect to the control group: employers may lay off workers who are less productive and have less future earning potential. Von Wachter and others (2011) conduct an in-depth investigation of this question and conclude that earnings losses based on equation 1 are robust to a range of important sensitivity checks. The presence of worker fixed effects in equation 1 implies that selection based on fixed worker attributes with a time-invariant effect on earnings poses no problem. However, different trends in counterfactual earnings between displaced workers and the control group may introduce a bias. For example, it is well known that different parts of the earnings distribution experience different earnings growth rates (see, for example, Autor and Katz 1999). Since displaced workers have lower average earnings before displacement than nondisplaced workers, our regression models include interactions between average earnings in the 5 years before displacement and fixed effects for calendar years. Von Wachter and others also present estimates that include differential trends by two-digit industry and by other observable characteristics of workers and firms before displacement. The estimates are reasonably robust to these modifications and decline only somewhat with the inclusion of industry-specific trends.

However, ex ante differences in unobservable characteristics between treatment and control groups can still lead to different counterfactual earn- 
ings trends. In this context, von Wachter and others (2011) address two types of selection: that within and that between employers. To address the concern that displaced workers are negatively selected on potential unobserved earnings trends within firms, they replicate equation 1 using the mass-layoff event at the firm level as an instrumental variable for displacement. That is, they use a dummy for the year of the mass layoff at the firm, $D_{f(i) t}^{k}$, where $f(i)$ is the worker's employer, to instrument for the dummy of the individual layoff $\left(D_{i t}^{k}\right)$. Hence, the comparison is now between the earnings of all workers at firms undergoing mass layoffs and the earnings of all workers at non-mass-layoff firms. Using this type of firm-level indicator to instrument for displacement, and controlling for differential trends by pre-mass-layoff characteristics at the firm level, von Wachter and others obtain results very similar to those reported here based on equation 1 . This instrumental variables estimator is also robust to the presence of non-masslayoff separators, since the instrument should be orthogonal to the rate of retirement or voluntary mobility.

To address the possible concern that workers with lower potential earnings trends sort into firms more likely to experience mass layoffs, von Wachter and others (2011) follow previous work and consider a version of equation 1 that includes an interaction between year effects and firm fixed effects. This specification yields somewhat smaller estimated earnings losses, because the losses of workers remaining at firms with mass layoffs are now subtracted from the losses of the displaced workers. It is not clear whether the decline in earnings for those remaining at masslayoff firms should be subtracted or treated as part of the outcome. In any event, the estimated losses for the displaced workers remain substantial and very persistent. Von Wachter and others conclude that estimates based on equation 1, on which we rely, are robust to a range of important sensitivity checks. Hence, despite some variation depending on the exact specification, we believe our calculations based on estimated versions of equation 1 provide a reasonable characterization of the magnitude and persistence of the individual earnings losses caused by job displacement.

\section{Other Costs of Job Displacement and Unemployment}

Section II focused on earnings losses associated with displacement events. We turn now to the effects of job displacement on other outcomes such as consumption, health, mortality, and children's educational achievement. We also present new evidence on cyclical movements in worker anxieties 
and perceptions about the risk of job loss and the ease or difficulty of job finding.

\section{III.A. Effects on Income, Consumption, and Employment Stability}

It is not easy to estimate the effects of job displacement on consumption and income. Few, if any, data sets that track large numbers of workers over time contain high-quality information about consumption outcomes. Likewise, very few data sets that track large numbers of workers include the data on earnings, asset incomes, and public and private transfer payments needed to identify income responses to job displacement events. Moreover, transfer payments are understated greatly in many household surveys that include such information (Meyer, Mok, and Sullivan 2010).

The few studies that estimate the effects of job loss or unemployment on consumption typically find sizable near-term declines in consumption expenditure but lack evidence on long-term consumption responses. See Gruber (1997) and Stephens (2004), for example. The consumption responses tend to be concentrated at the lower end of the income distribution (Browning and Crossley 2001, Congressional Budget Office 2004). Although transfer programs often mitigate the earnings loss due to job displacement, the replacement amounts are quite modest compared with our estimates of present-value earnings losses. Even the generous, longlasting benefits available under the German unemployment insurance system replace only a modest share of the earnings loss associated with job displacement (Schmieder, von Wachter, and Bender 2009).

Previous research also finds that job displacement leads to other adverse consequences. Lasting postdisplacement earnings shortfalls occur alongside lower job stability, greater earnings instability, recurring spells of joblessness, and multiple switches of industry or occupation (Stevens 1997, von Wachter and others 2011). Much of the increased mobility between jobs, between industries, and between occupations probably reflects privately and socially beneficial adjustments. On average, however, displaced workers who immediately find a stable job in their predisplacement industry obtain significantly higher earnings. Lower job stability and higher earnings volatility persist up to 10 years after displacement. Thus, there is no indication that laid-off workers trade a lower earnings level for a more stable path of employment and earnings.

\section{III.B. Effects on Health, Mortality, Emotional Well-Being, and Family}

There is also evidence that displaced workers suffer short- and longterm declines in health. Survey-based research in epidemiology finds that 
layoffs and unemployment spells involve a higher incidence of stressrelated health problems such as strokes and heart attacks (see, for example, Burgard, Brand, and House 2007).

Whereas studies of self-reported health and job loss outcomes face significant challenges related to measurement error and to recall and selection bias, the analysis of mortality outcomes can exploit large administrative data sources that are less subject to these problems. Sullivan and von Wachter (2009) study the effects of job displacement on mortality outcomes over the 20 years following displacement, using administrative data on earnings and employers from the Pennsylvania UI system and mortality data from the SSA. Their results show that mature men who lost stable jobs in Pennsylvania during the early 1980s experienced near-term increases in mortality rates of up to 100 percent. The initial impact on mortality falls over time, but it remains significantly higher for job losers than for comparable workers throughout the 20 -year postdisplacement period. If sustained until the end of life, the higher mortality rates for displaced workers imply a reduction in life expectancy of 1 to 1.5 years.

Because the 1980s recession was especially deep in Pennsylvania and involved unusually large earnings losses for displaced workers, the mortality effects estimated by Sullivan and von Wachter (2009) reflect a very bad case scenario. It is reasonable to expect smaller mortality effects of job displacements in most other years and places. Unfortunately, labor market conditions nationwide in the past 3 years have also been dismal, with persistently high unemployment rates. Thus, the mortality estimates in Sullivan and von Wachter may well provide a suitable guide to mortality effects for recently displaced American workers. The available evidence indicates that job displacement also raises mortality rates in countries with universal public health insurance systems and generous social welfare systems, such as Sweden (Eliason and Storrie 2009) and Norway (Rege, Telle, and Votruba 2009). These studies find higher mortality rates in the years following job displacement, but they contain little information about longterm effects.

Several studies point to short- and long-term effects of layoffs on the children and families of job losers and unemployed workers. In the short run, parental job loss reduces the schooling achievement of children (Stevens and Schaller 2011). In the long run, it appears that a lasting reduction in the earnings of fathers reduces the earnings prospects of their sons (Oreopoulos, Page, and Stevens 2008). Patrick Wightman (2009) also finds that parental job loss is harmful for the educational attainment and cognitive development of children. Other studies find that layoffs raise the incidence 
of divorce, reduce fertility, reduce home ownership, and increase the rate of application to and entry into disability insurance programs (Charles and Stephens 2004, von Wachter and Handwerker 2009, Rupp and Stapleton 1995). Last but not least, and perhaps not surprisingly given the magnitude and range of adverse consequences discussed above, job loss and unemployment also lead to a reduction in happiness and life satisfaction (see Frey and Stutzer 2002).

Clearly, care should be taken in drawing welfare conclusions and policy prescriptions from the range of adverse consequences associated with job displacement. However, this brief review makes clear that job displacement entails a variety of significant short- and long-run costs for affected workers and their families. Neither the large present-value earnings losses we estimate nor the estimated consumption responses capture the full measure of costs associated with job displacement.

\section{III.C. Cyclical Movements in Worker Anxieties and Perceptions}

Given the severity of job displacement effects on earnings and other outcome measures, it is natural to ask how worker anxieties and perceptions about labor market conditions track actual conditions. Evidence on this issue is potentially informative in several respects. First, if recessions or high unemployment rates cause employed workers to become more fearful about layoffs and wage cuts, they involve psychological costs beyond the direct effects on job-losing workers and their families. Second, perceptions about labor market conditions are likely to influence search behavior by employed and unemployed workers, including those who experience a displacement event. Third, high worker anxiety about labor market conditions is likely to undermine consumer confidence and depress consumption expenditure. ${ }^{18}$ Fourth, perceptions about labor market conditions have important influences on policymaking, politics, and electoral outcomes. Because they potentially influence so many voters, anxieties about labor market conditions may have more important political consequences than actual conditions.

A long-running source of data on perceptions about labor market conditions is the General Social Survey (GSS), a repeated cross-sectional

18. Stephens (2004) provides survey-based evidence that subjective assessments of job loss probabilities have considerable predictive power for future layoffs at the individual level, even when conditioning on standard demographic variables that are correlated with layoff risks. Nevertheless, his main empirical specification yields no evidence of a relationship between job loss expectations and household consumption conditional upon losing a job. 
household survey conducted since 1972. The GSS includes two categorical response questions that are useful for gauging cyclical movements in perceptions about labor market conditions. One question asks the respondent about the perceived likelihood that he or she will lose a job or be laid off in the next 12 months. The other asks about the perceived difficulty of finding a job with the same income and fringe benefits as the respondent's current job.

The top panel of figure 7 shows, for each available year in the GSS, the percentage of prime-age workers who consider it "very likely" or "fairly likely" that they will lose a job or be laid off in the next 12 months. The figure plots these values against the average CPS unemployment rate in the 5-month window that brackets the corresponding GSS interview months. There is a strong, positive relationship: an increase in the prime-age unemployment rate from 4 percent to 8 percent raises from 10 percent to 15 percent the share of prime-age workers who perceive job loss as fairly or very likely. The online appendix shows a very similar pattern for all employed workers 18 to 64 years of age.

The bottom panel of figure 7 shows the percent of prime-age workers who perceive it to be "not easy" to find a job with income and fringe benefits similar to those in their current job. Plotting these values against contemporaneous unemployment rates, we again find a strong relationship: an increase in the prime-age unemployment rate from 4 percent to 8 percent raises from 35 percent to 52 percent the share of prime-age workers who regard it as hard to find another job with a comparable compensation package. In this context it is also worth noting that quit rates are highly procyclical (see, for example, Davis and others 2012). Quit rates plummeted in the most recent recession and remain extraordinarily low, another indication that workers perceive good jobs as hard to find.

Gallup polls provide another long-running, consistent source of data on perceived labor market conditions. The Gallup data cover a shorter time period than the GSS data, but they pertain to a highly eventful period in terms of economic developments. In addition, one of the Gallup measures is available at a (roughly) monthly frequency, which is useful for assessing the shorter-term relationship between perceived and actual conditions. Figure 8 draws on the Gallup data to plot over time the percent of adult interviewees who respond yes to the following question: "Thinking about the job situation in America today, would you say that it is now a good time or a bad time to find a quality job?" The responses are highly cyclically sensitive. As the labor market tightened, the share of yes responses rose from about 20 percent in early 2003 to nearly 50 percent in the first 
Figure 7. Perceived Likelihoods of Job Loss and Job Finding versus the Contemporaneous Unemployment Rate, Prime-Age Workers, 1977-2010
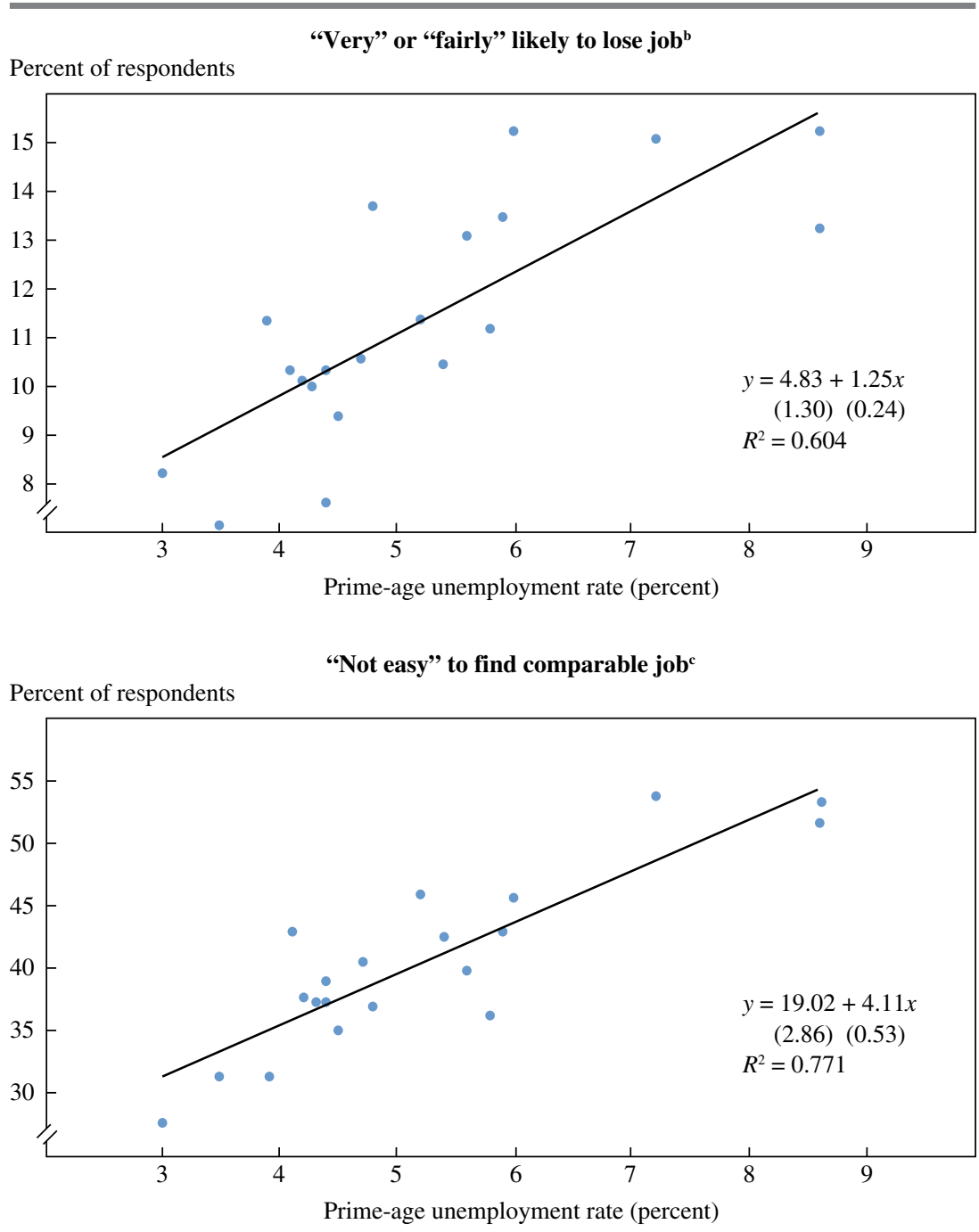

Source: Authors' calculations using tabulations of micro data from the GSS and unemployment data from the CPS.

a. Each point corresponds to a GSS survey year and plots the share of prime-age respondents in that year giving the indicated response against the average of seasonally adjusted monthly unemployment rates in January through May of the same year. (GSS interviews take place in February, March, and April.) Prime-age workers are employed adults aged 25 to 54, excluding active-duty armed forces, persons who report self-employment as their main job, and institutionalized persons. Oversamples of blacks in the GSS in certain years are excluded. Responses are weighted using the WTTSALL variable.

b. The full question is "Thinking about the next 12 months, how likely do you think it is that you will lose your job or be laid off—very likely, fairly likely, not too likely, or not at all likely?" (GSS variable JOBLOSE).

c. The full question is "About how easy would it be for you to find a job with another employer with approximately the same income and fringe benefits you now have? Would you say very easy, somewhat easy, or not easy at all?" (GSS variable JOBFIND). 
Figure 8. Perceived Availability of Good Jobs, March 2002 to June $2011^{\text {a }}$

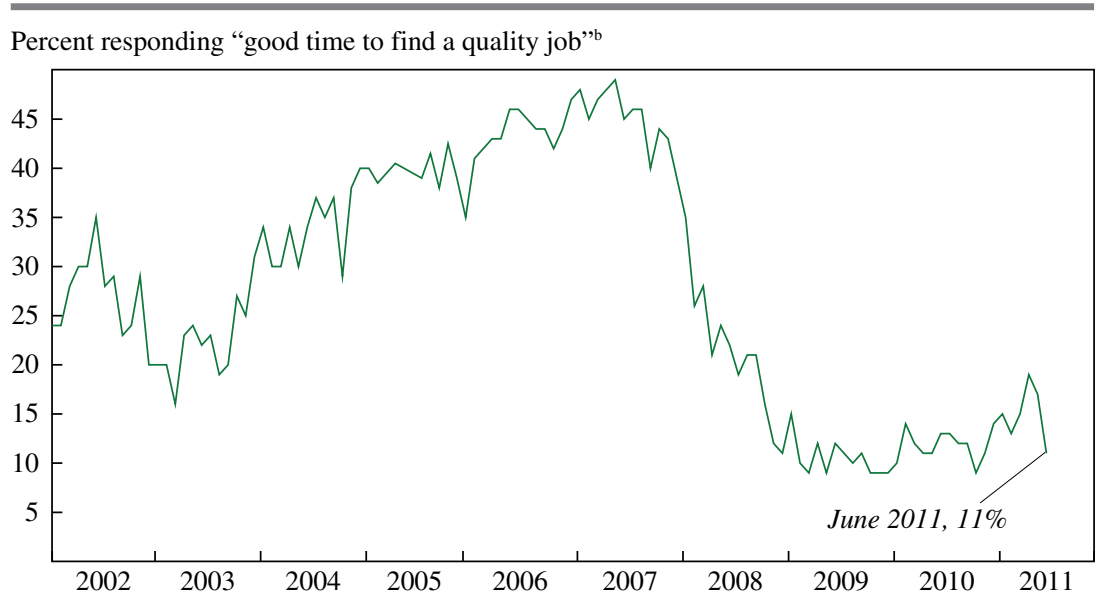

Sources: Gallup polling data at www.gallup.com/file/poll/148130/Quality_Job_110620.pdf.

a. Based on telephone interviews with random samples of adults, 18 years and older, living in the 50 U.S. states and the District of Columbia. Gallup conducts the interviews approximately once per month, and each round of interviews takes place over 3 or 4 days. We date each survey according to the first day of interviews.

b. The survey question is "Thinking about the job situation in America today, would you say that it is now a good time or a bad time to find a quality job?"

half of 2007. It then dropped to about 10 percent over the next 2 years and has remained at very low levels ever since. This evidence suggests that perceptions about labor market conditions respond rapidly to actual conditions.

Table 3 reports data from Gallup polls conducted during the month of August in 1997 and every year from 2003 to 2011. The table shows a tremendous increase in worker anxiety levels following the peak of the financial crisis in the latter part of 2008 and early 2009. The percentages of employed adults expressing worries that they personally would experience a cutback in hours, a wage cut, a benefit cut, or a layoff in the near future jumped dramatically. After some lessening between August 2009 and August 2010, the most recent data for August 2011 show worker anxiety returning to peak or near-peak levels.

In summary, the evidence presented in figures 7 and 8 and table 3 indicates that worker perceptions about labor market conditions are closely attuned to actual conditions. The Gallup polling data, in particular, point to a dramatic deterioration in perceptions about labor market conditions and prospects after the financial crisis-a deterioration that persists to the 
Table 3. Percent of Employed Adults Who Worry They Will Experience an Adverse Job-Related Event in the Near Future

\begin{tabular}{lcccc}
\hline & \multicolumn{4}{c}{ Adverse event $^{\mathrm{a}}$} \\
\cline { 2 - 5 } Survey month & Cut in hours & Cut in wages & Cut in benefits & Layoff \\
\hline August 1997 & 15 & 17 & 34 & 20 \\
August 2003 & 15 & 17 & 31 & 19 \\
August 2004 & 14 & 17 & 28 & 20 \\
August 2005 & 13 & 14 & 28 & 15 \\
August 2006 & 16 & 19 & 30 & 17 \\
August 2007 & 12 & 14 & 29 & 14 \\
August 2008 & 14 & 16 & 27 & 15 \\
August 2009 & 27 & 32 & 46 & 31 \\
August 2010 & 25 & 26 & 39 & 26 \\
August 2011 & 30 & 33 & 44 & 30 \\
\hline
\end{tabular}

Source: Reproduced from Gallup Polling data at www.gallup.com/poll/1720/work-work-place.aspx and www.gallup.com/poll/149261/Worries-Job-Cutbacks-Return-Record-Highs.aspx.

a. Based on polling of workers employed full or part time. The survey question is "Next, please indicate whether you are worried or not worried about each of the following happening to you, personally, in the near future. How about [the following are rotated] that your hours at work will be cut back? that your wages will be reduced? that your benefits will be reduced? that you will be laid off?"

present day and that involves widespread concerns about layoff risks, wage and benefit cuts, shorter hours, and the difficulty of finding a good job. Whether or not these fears show up in realized earnings outcomes, they involve psychological costs in the form of heightened anxiety for much of the population.

\section{The Effects of Job Loss in Leading Theoretical Models of Unemployment and Labor Market Dynamics}

Mortensen and Pissarides (1994) present an equilibrium search-and-matching model that, in various formulations, has become the leading framework for analyzing aggregate unemployment fluctuations. We now evaluate how well certain versions of the Mortensen-Pissarides (MP) model account for our evidence on the magnitude and cyclicality of the earnings losses associated with job displacement. ${ }^{19}$

19. There appear to be few previous efforts to evaluate whether equilibrium search-andmatching models can account for the earnings losses associated with job displacement. An exception is Den Haan, Ramey, and Watson (2000). Davis (2005) provides some backof-the-envelope calculations. The loss of earnings potential upon job loss is an important element in the theoretical model of high European unemployment rates developed by Ljungqvist and Sargent (1998). 


\section{IV.A. MP Models of Unemployment Fluctuations}

Shimer (2005) considers a basic version of the MP model with riskneutral workers and firms, uniform match quality, Nash bargaining, and a constant rate of job destruction and job loss. Aggregate shocks drive employer decisions about vacancy posting and fluctuations in job creation, job finding, and unemployment. Shimer shows that the basic MP model delivers too little volatility in unemployment for reasonable specifications of the aggregate shock process (see also Costain and Reiter 2008). Under Nash bargaining, the equilibrium wage largely absorbs shocks to labor productivity in the basic model. As a result, realistic shocks have little impact on employer incentives to post vacancies, and the model generates small equilibrium responses in job finding rates, hiring, and unemployment. This unemployment volatility puzzle has motivated a great deal of research in recent years.

One prominent strand of this research stresses the consequences of wage rigidities. ${ }^{20}$ Hall and Milgrom (2008), for example, step away from Nash bargaining while retaining privately efficient compensation and separation outcomes. They replace Nash bargaining with the alternating-offer bargaining protocol proposed by Ken Binmore, Ariel Rubinstein, and Asher Wolinsky (1986). Whereas the standard Nash wage bargain treats termination of the match opportunity as the threat point, the threat point in Hall and Milgrom's "credible bargaining" setup is a short delay followed, with high probability, by a resumption of bargaining. This change in bargaining regime goes a long way to insulate the equilibrium wage bargain from aggregate shocks and outside labor market conditions.

A key point is that the cost of a small delay during the bargaining process is less cyclical than the value of outside opportunities. Hence, closing the basic MP model in the manner of Hall and Milgrom leads to greater sensitivity of the employer surplus value to aggregate shocks and bigger responses in vacancies, job finding rates, and unemployment. Hall and Milgrom show that their specification of the bargaining environment resolves the unemployment volatility puzzle in a reasonably calibrated version of the basic MP model.

In our analysis below, we adopt Hall and Milgrom's credible bargaining version of the basic MP model and two versions with Nash bargaining. We follow this approach for two reasons. First, Hall and Milgrom offer perhaps the most successful version of the basic MP model in terms of explaining

20. See, for example, Shimer (2004, 2010), Hall (2005), Gertler and Trigari (2009), and Kennan (2009). Mortensen and Nagypal (2007), Ramey (2008), Pissarides (2009), Burgess and Turon (2010), and Eyigungor (2010), among others, propose alternative resolutions to the unemployment volatility puzzle. 
the cyclical behavior of job finding rates, vacancies, and unemployment. Second, by comparing the credible bargaining and Nash versions of the model, we can determine whether a particular form of wage rigidity improves the model's ability to account for the facts about earnings losses associated with job loss.

Despite much attention to the basic MP model in recent work, the model misses some first-order features of labor market fluctuations. The basic MP model cannot reproduce the recessionary spikes in job destruction, job loss, and unemployment inflows depicted in figures 1 and 2. Moreover, the model has no role for hires and separations apart from job flows. There is no search by employed workers, no job-to-job movement, and no replacement hiring. As a related point, the basic model entails no heterogeneity of productivity, match surplus values, or wages. This sort of heterogeneity seems important for generating large earnings losses due to job loss. Given these limitations, we also consider a model of Burgess and Turon (2010) that extends Mortensen and Pissarides (1994) by incorporating search on the job and other changes. Burgess and Turon's model produces hires and separations apart from job flows and recessionary spikes in job destruction, job loss, and unemployment inflows.

There are also good reasons to anticipate that the model of Burgess and Turon will generate larger earnings losses associated with job loss than the basic MP model. Like models by Kenneth Burdett and Mortensen (1998) and by Fabien Postel-Vinay and Jean-Marc Robin (2002) and other models that include search on the job, their model generates persistent heterogeneity in match surplus values and wages for workers of a given quality. It also delivers a job "ladder" whereby newly reemployed workers tend to obtain jobs on the lower rungs of the wage distribution initially and to move up the wage distribution over time through search on the job. This job ladder feature prolongs the period of earnings recovery after displacement. Finally, Andreas Hornstein, Per Krusell, and Giovanni Violante (2010) show that plausibly parametrized versions of basic search models yield very modest levels of frictional wage dispersion, which implies little scope for earnings losses due to job loss when unemployment spells are short. Hornstein and others also consider several extensions to basic search models, and among those they consider, the only ones that offer much scope for cross-sectional wage dispersion are models with search on the job.

\section{IV.B. Income and Earnings Losses in the Basic MP Model}

Table 4 reports statistics for three versions of the basic MP model: the credible bargaining version of Hall and Milgrom (2008) and two versions 
with Nash bargaining - a standard calibration similar to that of Shimer (2005) and another calibration similar to that of Marcus Hagedorn and Iourii Manovskii (2008). These two calibrations differ chiefly in the level of income imputed to the unemployed, which we interpret as the sum of UI benefits, the value of additional leisure and home production activity, and any savings on work-related costs. Hagedorn and Manovskii set this value to a level nearly as large as the productivity of the employed, thereby amplifying the equilibrium response of unemployment to aggregate shocks. The standard calibration involves a much larger gap between productivity and the imputed income value of unemployment, yielding much smaller equilibrium responses to shocks of a given size. Our calibrations follow Hall and Milgrom (2008) in their choice of parameter values for each version of the basic MP model. See the online appendix for a detailed discussion of the model simulations and our calculations for the present-value losses associated with job loss.

The first row of table 4 highlights an important message: job loss and unemployment are a rather inconsequential event for persons living in the basic MP world. With a 5 percent annual discount rate, job loss reduces the present value of income by about 0.2 percent in the MP-CB and standard MP-Nash versions of the model and by less than 0.05 percent in the Hagedorn-Manovskii calibration. We compute these present-value income losses directly from value functions. That is, for each of five aggregate states we calculate the difference between the asset value of employment and the asset value of unemployment, expressing the difference relative to the former. Performing this calculation for all five aggregate states yields the reported ranges. If these results capture the real-world costs of job loss, one might well wonder why all the fuss - why are job loss and unemployment perceived as important economic phenomena and potent political issues?

The rest of the table reports statistics on unemployment, job finding, and the distribution of present-value income and earnings losses for the different models. To compute these statistics, we simulate aggregate and individual paths. Starting in the middle aggregate state, we simulate 1,000 aggregate paths for each version of the model, letting each simulation run for 20 years $(5,000$ days at 250 working days per year). Along each aggregate path, we simulate paths for large numbers of workers who either lose jobs or remain employed on day 1 . Flow income equals the annuity value of the wage bargain when employed and the imputed flow value of unemployment otherwise. The PDV of income includes the discounted asset value of the individual's realized terminal state. To compute the realized 
Table 4. Present-Value Income and Earnings Losses Associated with Job Loss in the Basic Mortensen-Pissarides Model ${ }^{\mathrm{a}}$

Percent

\begin{tabular}{|c|c|c|c|}
\hline & \multicolumn{3}{|c|}{ Basic MP model version } \\
\hline & $\begin{array}{l}\text { Nash version, } \\
\text { standard } \\
\text { calibration }^{\mathrm{b}}\end{array}$ & $\begin{array}{l}\text { Nash version, } \\
\text { Hagedorn and } \\
\text { Manovskii (2008) } \\
\text { calibration }\end{array}$ & $\begin{array}{l}\text { Credible bargaining } \\
\text { version, Hall and } \\
\text { Milgrom (2008) } \\
\text { calibration }^{c}\end{array}$ \\
\hline $\begin{array}{l}\text { Range of mean PDV } \\
\text { income losses over five } \\
\text { aggregate states }^{\mathrm{d}}\end{array}$ & 0.20 to 0.22 & 0.044 to 0.047 & 0.20 to 0.23 \\
\hline \multicolumn{4}{|l|}{ Simulation outcomes ${ }^{\mathrm{e}}$} \\
\hline \multicolumn{4}{|l|}{ All aggregate paths } \\
\hline Mean unemployment rate & 6.6 & 6.7 & 6.7 \\
\hline Monthly job finding rate ${ }^{f}$ & 43 & 43 & 43 \\
\hline Mean PDV income loss ${ }^{g}$ & 0.23 & 0.05 & 0.23 \\
\hline $\begin{array}{l}\text { 10th-90th percentile } \\
\text { range, income losses }\end{array}$ & -0.55 to 1.07 & -0.29 to 0.40 & -0.51 to 1.04 \\
\hline Mean PDV earnings loss ${ }^{\mathrm{h}}$ & & & 1.28 \\
\hline $\begin{array}{l}\text { 10th-90th percentile } \\
\text { range, earnings losses }\end{array}$ & & & -2.62 to 5.72 \\
\hline \multicolumn{4}{|l|}{ Aggregate boom paths ${ }^{\mathrm{i}}$} \\
\hline Mean unemployment rate & 6.5 & 6.4 & 6.4 \\
\hline Monthly job finding rate ${ }^{f}$ & 43 & 44 & 44 \\
\hline Mean income loss ${ }^{\mathrm{g}}$ & -0.19 & -0.26 & -0.12 \\
\hline $\begin{array}{l}\text { 10th-90th percentile } \\
\text { range, income losses }\end{array}$ & -0.84 to 0.56 & -0.39 to -0.11 & -0.75 to 0.60 \\
\hline Mean PDV earnings loss ${ }^{\mathrm{h}}$ & & & 1.14 \\
\hline $\begin{array}{l}\text { 10th-90th percentile } \\
\text { range, earnings losses }\end{array}$ & & & -2.73 to 5.53 \\
\hline \multicolumn{4}{|l|}{ Aggregate bust paths ${ }^{j}$} \\
\hline Mean unemployment rate & 6.7 & 7.0 & 7.0 \\
\hline Monthly job finding rate ${ }^{f}$ & 43 & 41 & 42 \\
\hline Mean income loss ${ }^{\mathrm{g}}$ & 0.66 & 0.37 & 0.59 \\
\hline $\begin{array}{l}\text { 10th-90th percentile } \\
\text { range, income losses }\end{array}$ & 0.02 to 1.38 & 0.26 to 0.51 & -0.08 to 1.35 \\
\hline $\begin{array}{l}\text { 99th-percentile } \\
\text { income loss }\end{array}$ & 2.18 & 0.66 & 2.20 \\
\hline Mean PDV earnings loss ${ }^{\mathrm{h}}$ & & & 1.42 \\
\hline $\begin{array}{l}\text { 10th-90th percentile } \\
\text { range, earnings losses }\end{array}$ & & & -2.49 to 5.87 \\
\hline $\begin{array}{l}\text { 99th-percentile } \\
\text { earnings loss }\end{array}$ & & & 10.81 \\
\hline
\end{tabular}


Notes to table 4:

Source: Authors' calculations.

a. All present-value calculations use a 5 percent annual discount rate. All model calibrations follow Hall and Milgrom (2008) in their choice of parameter values and the transition matrix of a five-state Markov process for aggregate shocks. See the online appendix for a more detailed description of the simulations and calculations.

b. Calibration is similar to that in Shimer (2005) and Hall (2005).

c. Model entails sequential bargaining with disagreement costs à la Binmore, Rubinstein, and Wolinsky (1986). Calibration is that of Hall and Milgrom (2008).

d. We compute the present-value income losses in the top row directly from value functions. For each aggregate state, we calculate the difference between the asset value of employment and the asset value of unemployment and express the difference relative to the asset value of employment. Performing this calculation for the five aggregate states yields the reported ranges.

e. Each indicated model is simulated for 1,000 draws of the aggregate path, with each draw starting from the middle aggregate state and evolving according to the aggregate transition matrix. Each draw is simulated for 5,000 working days (20 years at 250 working days per year). The realized paths are tracked for 5,000 day-1 job losers and 1,000 day-1 employed persons on each of the 1,000 aggregate paths.

f. Calculated as $\theta \sum_{i=1}^{25}(1-\theta)^{i-1}$, where $\theta$ is the daily job finding rate, assuming 25 job seeking days per month.

g. For the income calculations, an individual receives the imputed income value of leisure if unemployed on a given day, and the annuity value of the wage bargain if employed. At the end of the simulation horizon, each individual is assigned the asset value associated with that individual's state on day 5,000. This results in a realized income path plus terminal value for each individual, which is then used to compute the realized PDV of income for an unemployed worker as of day 1 . This quantity is then compared with that of the mean realized present-value income of the day- 1 employed persons on the same aggregate path.

h. For the earnings calculations, each individual is assigned zero earnings if unemployed and the annuity value of the wage bargain if employed. To focus on PDV earnings over a 20-year horizon comparable to the empirical estimates in section II, the terminal value is set to zero at the end of the 5,000-day simulation horizon. The PDVs of the realized earnings paths for individuals who become unemployed on day 1 are then compared with the mean realized present-value earnings for 1,000 individuals who remain employed on day 1 on the same aggregate path. Because earnings loss statistics are very similar across all three variants of the MP model, results are reported only for the credible bargaining version of the basic MP model.

i. The 1,000 aggregate paths are ranked by realized mean PDV income or earnings loss. This panel reports statistics for the paths ranked from 90 to 110 (the 20 paths nearest the 10 th percentile) by this metric.

j. Statistics are reported for the paths ranked from 890 to 910 (the 20 paths nearest the 90 th percentile) by mean PDV income or earnings loss.

income loss for a day-1 job loser, we compare the PDV of that individual's realized income path with the mean realized PDV of income for persons who remain employed on day 1 on the same aggregate path. In this way, by comparing day-1 job losers with persons who remain employed along the same aggregate path, we obtain a comparison between the treatment group (day-1 job losers) and the controls (day-1 employed).

To compute the realized earnings loss for a day-1 job loser, we compare the PDV of that individual's realized earnings path over the 20-year 
horizon with the mean PDV of realized earnings for individuals living on the same aggregate path who remain employed on day 1 . Earnings equal the wage when employed and zero when unemployed. We set the terminal value to zero to match the 20-year horizon in our empirical estimates of PDV earnings losses. Thus, the earnings losses in table 4 are larger than the corresponding income losses for two reasons: earnings exclude the imputed income value of unemployment, and we set terminal values to zero in the earnings comparisons.

Consider the results for the MP-CB model in the first panel of simulations in table 4 . Averaging over all day- 1 job losers on all aggregate paths yields an average realized PDV income loss of 0.23 percent. This figure essentially replicates the income loss result for the MP-CB model in the top row, as it should. However, the simulation approach enables us to compute the full distribution of outcomes: the 90th-percentile income loss in the MP-CB version is only 1.04 percent, still a rather modest value, and job losers at the 10th percentile of the distribution actually experience a gain of 0.51 percent in PDV income.

Turning to earnings losses, we report results for the MP-CB version only, because the other two versions yield very similar results. Mean PDV earnings losses are 1.28 percent in the basic MP model—an order of magnitude smaller than the 11.9 percent figure in the last column and first row of table 1. One potential concern about this earnings loss comparison is that table 1 considers losses associated with job displacement events, which by design exclude many job loss events that involve little or no loss of earnings or income. So there is a sense in which we have compared average job loss outcomes in the basic MP model with bad-case outcomes in the data. Although this argument has some force, we do not find it persuasive. The estimated earnings losses reported in section II pertain to an ex ante identifiable group of workers (men 50 or younger with 3 or more years of job tenure at firms with 50 or more employees), and this group accounts for a large share of U.S. employment. We would like to have a theoretical model that explains the magnitude and cyclicality of the PDV earnings losses associated with job loss for this large group.

The remaining panels in table 4 consider selected aggregate paths defined by the mean realized PDV income or earnings losses. "Boom" paths are those near the 10th percentile of average losses for day-1 job losers, and "bust" paths are those near the 90th percentile. Mean PDV income losses remain small along both boom and bust paths. Even when we isolate the worst 1 percent of individual outcomes along the bust paths, the PDV income 
losses amount to only 2.2 percent in the $\mathrm{CB}$ and standard Nash versions of the model and only 0.7 percent in the Hagedorn-Manovskii calibration. In short, the basic MP model cannot produce large welfare losses for job losers, even at the extremes of aggregate and individual outcomes. The model can produce large PDV earnings losses at the extremes of the distribution of individual outcomes. For example, the worst 1 percent of individual outcomes yield earnings losses comparable to the mean loss reported in table $1 .{ }^{21}$ This result, however, hardly amounts to a success for the model.

Why are the consequences of job loss so modest in the basic MP model? Two aspects of the model deliver the result almost immediately. First, wages are uniform in the cross section, so that unemployment spells are the only source of earnings loss upon job loss. Second, when calibrated to job finding rates typical of the postwar U.S. experience, expected unemployment durations are short, about 2 or 3 months. Short unemployment spells coupled with uniform wages in the cross section imply small earnings losses associated with job loss.

The basic MP model also implies a close relationship between the cost of job loss to the worker and the vacancy supply condition (as has been stressed to us by Robert Hall). Given free entry, the zero-profit condition for job-creating employers says that the daily vacancy filling rate times the asset value of a filled job equals the daily flow cost of maintaining a vacancy. The JOLTS data imply a vacancy filling rate of about 5 percent per day. Drawing on work by Jose Silva and Manuel Toledo (2009) and Hagedorn and Manovskii (2008), Hall and Milgrom (2008) conclude that the daily flow cost of a vacancy is about one-half of a worker's daily output. Thus, the employer's asset value of a newly filled job is equivalent to about 10 days of the output generated by a (newly hired) worker. If employer and worker share equally in the surplus generated by a new match, then the worker's value of transitioning from unemployment to employment is also about 10 days of output. In other words, not much value is at stake in the creation and destruction of employment relationships in the basic MP

21. We could refine the treatment-control comparisons in table 4 by replicating the employment stability criterion used for controls in section II. This type of refinement may make sense in future research. Given the uniformity of wages and the small consequences of job loss in table 4, however, we do not think the basic MP model can explain the evidence on earnings losses or rationalize strong concerns about job loss and unemployment. 
model. Richer models in the MP class need not imply such a tight relationship between the cost of filling a new job and the surplus value of the average existing job.

In summary, we draw three conclusions from table 4 and the related discussion. First, job loss is a rather inconsequential event for individual welfare in the basic MP model, even at the extremes of individual and aggregate outcomes. Second, the basic MP model cannot rationalize the empirical evidence on PDV earnings losses associated with job displacement. Third, although wage rigidity of the form considered by Hall and Milgrom (2008) greatly improves the ability of the basic MP model to explain aggregate unemployment fluctuations, it does not bring the model closer to the evidence on the magnitude and cyclicality of earnings losses associated with job displacement.

\section{IV.C. Losses in an MP Model with Job Destruction Spikes and Search on the Job}

Burgess and Turon (2010) depart from Mortensen and Pissarides (1994) by introducing search on the job, at a cost, and by adopting a different vacancy creation process that gives meaning to the concept of a job apart from an employer-worker match. Specifically, they assume a finite supply elasticity of potential new job creation each period, so that firms find it optimal to refill certain jobs left open by departing workers. Like Mortensen and Pissarides (1994), their model also differs from the basic MP model in capturing cross-sectional heterogeneity in match products and surplus values. These extensions lead to cross-sectional wage dispersion, a distinction between job flows and worker flows, and endogenous job destruction spikes in the wake of negative aggregate shocks. The model also gives rise to a job ladder that prolongs the recovery of predisplacement earnings for job-losing workers.

The model is set in continuous time. Idiosyncratic productivity shocks arrive according to independent Poisson processes, and aggregate productivity, $p$, follows a three-state Markov chain. When hit by an idiosyncratic shock, a job draws a new idiosyncratic productivity value in the interval $[-\sigma, \sigma]$, possibly higher or lower than the previous value. Optimizing behavior yields three idiosyncratic productivity thresholds, as shown in figure 9. If idiosyncratic productivity exceeds $S(p)$ in a filled job, the worker's net expected gains to search are negative. For productivity less than $S(p)$ in a filled job, the worker's net expected gains to search are positive. If the worker finds a vacant job, he quits and the firm decides whether to search for a replacement. It does so if idiosyncratic productivity exceeds $T(p)$; 
Figure 9. Idiosyncratic Productivity Thresholds for Job Destruction, Replacement Hiring, and On-the-Job Search in the Burgess-Turon Model

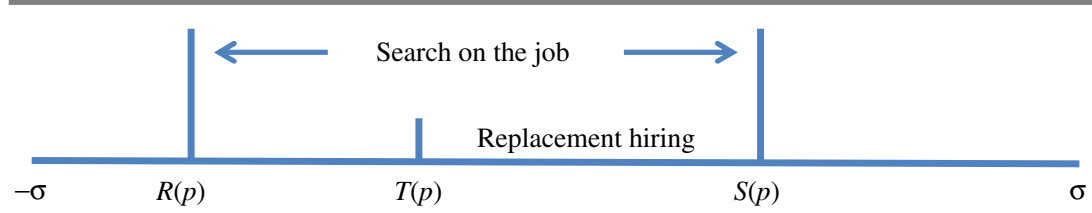

otherwise, it lets the job lapse. If a filled job draws a new idiosyncratic productivity value below $R(p)$, the job is destroyed and the worker experiences job loss. As the figure indicates, the productivity thresholds are functions of the aggregate state. A negative shock to $p$ shifts $R(p)$ to the right, triggering a burst of job destruction. An important implication is that job losses due to idiosyncratic shocks occur throughout the distribution of productivities, whereas job losses due to aggregate shocks occur only for low-value jobs.

Table 5 reports PDV income and earnings losses for the model of Burgess and Turon. We modify their calibration to generate job finding rates and unemployment spell durations comparable to postwar U.S. experience. ${ }^{22}$ The top panel reports results for a period of time corresponding to 3 months with no change in the aggregate state. The remaining two panels involve transitions between states and focus on outcomes for workers who lose jobs in the early part of a downturn, roughly corresponding to the recessionary spikes in job destruction and job loss seen in figures 1 and 2 . All loss calculations pertain to workers who separate from their employer in job destruction events and exclude separations that result from search on the job.

The first two rows of table 5 report PDV income and earnings losses for job losers in the good, middle, and bad aggregate states. We compute the income losses using differences in value functions at each level of idiosyncratic productivity, $\varepsilon$, and then integrate over the distribution of $\varepsilon$ that prevails in the indicated aggregate state to obtain the mean PDV income losses. These losses are larger than in the basic MP model, but they remain quite modest: about 0.3 to 0.4 percent.

For earnings losses we adopt a simulation approach similar to the one used for table 5. However, we now compare the realized PDV earnings of

22. See the online appendix for a version of table 5 that adopts their calibration, which is meant to match features of the British economy from 1964 to 1999. 
Table 5. Present-Value Income and Earnings Losses Due to Job Loss in the Burgess-Turon Model ${ }^{\mathrm{a}}$

Percent

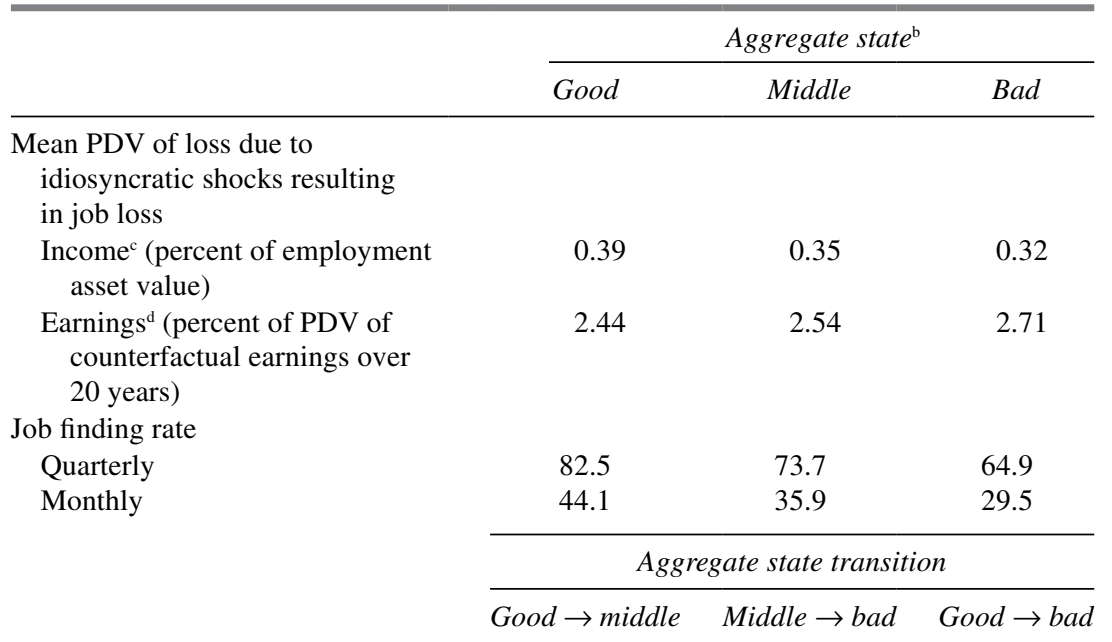

PDV income losses ${ }^{c}$ (percent of employment asset value)

Mean loss due to idiosyncratic

shocks that result in job loss, comparison with own past $\mathrm{e}^{\mathrm{e}}$

Mean loss due to aggregate

shock that results in job loss, comparison with own past

Inflow-weighted average ${ }^{f}$

0.61

0.55

0.80

Mean loss due to idiosyncratic

0.35

0.32

0.32

shocks that result in job loss, comparison with control group

Mean loss due to aggregate

0

0

0

shock that results in job loss, comparison with control group ${ }^{\mathrm{h}}$

Inflow-weighted average

0.33

0.30

PDV earnings losses ${ }^{\mathrm{d}}$ (percent of PDV of countrerfactual earnings over 20 years)

Mean loss due to idiosyncratic shocks that result in job loss, comparison with own past

Mean loss due to aggregate

shock that results in job loss, comparison with own past Inflow-weighted average

Mean loss due to idiosyncratic shocks that result in job loss, comparison with control group 
Table 5. Present-Value Income and Earnings Losses Due to Job Loss in the Burgess-Turon Model ${ }^{a}$ (Continued)

\begin{tabular}{cccc}
\hline & \multicolumn{3}{c}{ Aggregate state transition } \\
\cline { 2 - 4 } & Good $\rightarrow$ middle & Middle $\rightarrow$ bad & Good $\rightarrow$ bad \\
\hline $\begin{array}{c}\text { Mean loss due to aggregate shock } \\
\text { that results in job loss, } \\
\text { comparison with control group } \\
\text { Inflow-weighted average }\end{array}$ & 0 & 0 & 0 \\
\hline
\end{tabular}

Source: Authors' calculations.

a. Burgess and Turon's (2010) search-and-matching model differs from the basic MP model in capturing search on the job, a distinction between job flows and worker flows, heterogeneity in wages and match surplus values, and spikes in aggregate job destruction. It also adopts a different vacancy creation process that gives content to the concept of a job apart from the employer-worker match. Job destruction and job loss arise from negative aggregate shocks and sufficiently bad idiosyncratic shocks. We depart from Burgess and Turon's calibration (which was designed to match features of the U.K. economy) by increasing the arrival rate of idiosyncratic shocks (from 0.15 to 0.25 ) and the efficiency of the matching function (from 0.6 to 1.1). These changes yield more rapid flows through the unemployment pool and higher monthly job finding rates, roughly in line with U.S. outcomes. The unemployment rate is 5.2 percent in the middle state in our calibration. See the text for further description of the model and the online appendix for a detailed explanation of the loss calculations and the underlying simulations.

b. Results are for a period of time corresponding to 3 months with no change in the aggregate state.

c. Calculated from value function comparisons.

d. Calculations rely on simulations of aggregate and individual paths over 20-year horizons (80 quarters), where earnings are set to the wage if the individual is employed and to zero if not. The wage when employed depends on the aggregate state and the idiosyncratic productivity level of the job.

e. "Own past" comparisons calculate losses relative to the job loser's predisplacement employment value evaluated at the old aggregate state and expressed relative to the same employment value. The value of unemployment is calculated at the new aggregate state.

f. Inflow-weighted averages of PDV losses associated with idiosyncratic and aggregate shocks. The weights are given by the share of job loss due to idiosyncratic shocks during the quarter and the share triggered by a negative aggregate shock.

g. "Control group" comparisons calculate losses relative to the job loser's predisplacement employment value evaluated at the new aggregate state. The value of unemployment is also calculated at the new aggregate state.

h. Calculations that result in zero loss do so because all workers in the lower tail of the productivity distribution lose their jobs when hit by a negative aggregate productivity shock, and all get the value of unemployment in the new state.

workers who lose jobs characterized by a given $\varepsilon$ with the mean realized PDV earnings among workers who remain employed (in the displacement period) at the same value of $\varepsilon$. Once we obtain the comparison for each $\varepsilon$, we integrate with respect to the appropriate distribution to obtain the mean realized PDV earnings loss. As before, we use a 20-year horizon for the earnings calculations. The online appendix describes the model simulations and PDV calculations in detail.

The remaining panels consider job loss events that occur in the quarter when the economy gets hit by a negative aggregate shock. Job loss events now arise for two reasons. As before, a flow of negative idiosyncratic 
shocks produces a stream of job loss events. In addition, the negative aggregate shock erases the surplus value of marginal jobs, producing a burst of job destruction and job loss. All workers at jobs below the new, higher destruction threshold $R$ become unemployed in the wake of a negative aggregate shock. That is, for treatment-control comparisons conditional on the idiosyncratic productivity value $\varepsilon$, all workers below the new destruction threshold are in the same position. (Hence, losses are zero in the row in each panel that reports the "mean loss due to aggregate shock." ${ }^{23}$ For control group comparisons, job loss produces PDV income losses of about 0.3 percent in these "recession" periods. The disproportionate loss of marginal jobs in the wake of a negative aggregate shock pulls down the average present-value income loss. So the model of Burgess and Turon does not shed much light on why job loss events in recessions are more consequential.

With respect to earnings, our calibrated version of the Burgess and Turon model produces nontrivial PDV losses. For a given aggregate state, the losses reported in the top panel of table 5 range from 2.4 to 2.7 percent of PDV earnings, about one-quarter of the empirical PDV earnings losses reported in tables 1 and 2. Thus, search on the job and heterogeneity in match surplus values clearly help move the model closer to the evidence on the PDV earnings losses associated with job loss.

In this respect, the job ladder feature of the model plays an important role. The online appendix displays the cross-sectional wage function, the density of all filled jobs, and the density of first jobs for newly reemployed workers who leave unemployment. For our calibrated version of the model, the maximum wage in the good aggregate state exceeds the minimum wage by 49 percent. The density of first jobs is much more concentrated at the low end of the wage distribution than the density of all jobs. The average difference between the predisplacement wage and the wage on the first postdisplacement job is 10 percent in the good aggregate state, 8.4 percent in the middle state, and 6.7 percent in the bad state. These observations and statistics are different ways of saying that the model incorporates a significant job ladder.

A few additional remarks are in order. First, in generating the results in table 5, we do not impose a job tenure requirement on either displaced

23. In practice, empirical treatment-control comparisons do not perfectly condition on the idiosyncratic component of jobs and match values. However, as long as the empirical specification at least partly captures a disproportionate loss of marginal jobs in the wake of a negative aggregate shock, the composition effect we highlight here will also be present in the empirical estimates of earnings losses associated with job loss in a recession. 
workers or control group workers. Doing so may increase the earnings losses. Second, search intensity is a binary decision variable in the model of Burgess and Turon. Variable search intensity for employed workers, as in work by Matthias Hertweck (2010), may generate an elongated climb up the job ladder after displacement and, as a result, produce larger PDV earnings losses. ${ }^{24}$ We conclude that job ladder models can produce nontrivial earnings losses due to job displacement but are unlikely to account for the bulk of observed losses. For one thing, they do not explain why the earnings of displaced workers remain well below those of control group workers 10 or more years after displacement. Moreover, it does not appear that a pure job ladder model can rationalize the striking cyclical pattern in PDV earnings losses that we documented in section II.

\section{Concluding Remarks}

Long-tenure workers who lose jobs in mass-layoff events experience large and persistent earnings losses compared with otherwise similar workers who retain their jobs. That is the central message of a now-sizable literature on the earnings losses associated with job displacement. We focus on displacements from 1980 to 2005 among men 50 or younger with 3 or more years of prior job tenure. For this group, job loss in a mass-layoff event reduces the present value of earnings by an estimated $\$ 77,557$ (in 2000 dollars) over 20 years at a 5 percent annual discount rate, equivalent to 1.7 years of predisplacement earnings. Losses are larger for men with greater job tenure. They are smaller for women, even as a multiple of predisplacement earnings.

Present-value losses rise steeply with the unemployment rate at the time of displacement. The average loss equals 1.4 years of predisplacement earnings if unemployment at displacement is less than 6 percent, and 2.8 years if unemployment exceeds 8 percent. More generally, the evidence in tables 1 and 2 and figures 4 to 6 says that tight labor market conditions at displacement strongly improve the medium- and long-term future

24. Postel-Vinay and Robin (2002) consider a different model with search on the job and heterogeneity in productivity on both sides of the labor market. Employers have all the bargaining power, and newly reemployed workers start at the bottom of the wage distribution after an unemployment spell. When an employed worker finds an attractive outside opportunity, the incumbent employer may respond with a successful counteroffer (a wage increase). Thus, the model of Postel-Vinay and Robin also yields a prolonged earnings recovery path after job loss that is tied to search on the job, but wage gains may or may not coincide with job changes. 
earnings prospects of displaced workers. The highly procyclical behavior of job finding rates among the unemployed implies that tight labor market conditions strengthen near-term reemployment and earnings prospects as well. Seen in this light, economic policies that set the stage for strong growth and low unemployment are highly beneficial to displaced workers. Indeed, pro-growth policies may be the most efficient and cost-effective means available to policymakers to alleviate the hardships experienced by displaced workers.

Previous work shows that job displacement also has negative consequences for employment and earnings stability, household consumption expenditure, health and mortality outcomes, children's educational achievement, and subjective well-being. We present evidence that worker perceptions about layoff risks, job finding prospects, and the likelihood of wage cuts closely track cyclical fluctuations in actual labor market conditions. Perception measures point to a tremendous increase in worker anxieties about labor market prospects after the financial crisis of 2008, an increase that persists through August 2011. It seems likely that these high anxiety levels produce important stresses and psychological costs for a large segment of the population.

We also consider whether models of unemployment fluctuations along the lines of the canonical contribution by Mortensen and Pissarides (1994) can account for the earnings losses associated with job displacement. Basic versions of the MP model featured in much recent research imply theoretical earnings losses an order of magnitude smaller than empirical losses. The explanation is straightforward. The basic model has uniform wages in the cross section and, when calibrated to U.S. job finding rates, short unemployment spells. Thus, job loss has little impact on present-value earnings. Because so little is at stake in the destruction of employment relationships in the basic MP model, it cannot rationalize the earnings losses associated with job displacement.

Lastly, we evaluate an MP model of Burgess and Turon (2010) with search on the job and replacement hiring. Unlike the basic MP model, Burgess and Turon's model is at least qualitatively consistent with several first-order features of the data: cross-sectional wage dispersion, worker flows in excess of job flows, and recessionary spikes in job destruction and unemployment inflows. The model also exhibits a job ladder that prolongs the earnings recovery path after displacement. When calibrated to match U.S. job finding rates, job loss in the model produces present-value earnings losses that, on average, are about one-quarter of the mean empirical losses due to job displacement. This is a sizable improvement over the 
basic MP model, but it leaves a very large gap between theory and evidence. Moreover, the model cannot explain the larger losses for displacements that occur in recessions, because negative aggregate shocks trigger the destruction of lower-value jobs in the model.

In our view, a major shortcoming of existing MP models of unemployment fluctuations is their implication that job loss is a rather inconsequential event for the affected workers. The consequences of job displacement, and fears of displacement, are among the main reasons that recessions and high unemployment create so much concern in the general population. The negative consequences of job displacement are why unemployment is such a potent political issue. We also think the serious consequences of job displacement are a major reason that unemployment and unemployment fluctuations attract so much attention from economists.

It is important to put our criticism of MP models in proper context. We see MP models, in particular, and the larger class of Diamond-MortensenPissarides models as a great advance. These models deliver a coherent theory of frictional unemployment and its determinants. They provide an analytical framework for studying cyclical movements in unemployment, vacancies, job finding rates, and the joint dynamics of worker flows and job flows. They provide tools for analyzing search-and-matching behavior by employers and job seekers, and for studying the implications of searchand-matching frictions for wage dispersion and individual wage dynamics. These tools are widely used to study the effects of policies, wage setting arrangements, and other economic institutions on unemployment and a variety of other labor market outcomes.

We hope to see these models taken in directions that can explain large and lasting earnings losses at job displacement. There are potentially several ways to bring MP-type models closer to the evidence on the earnings losses associated with job displacement. Models that incorporate learning about match quality over time (as in Jovanovic 1979), the acquisition of specific skills through learning-by-doing on the job, and investments in specific training (as in Becker 1962) could yield substantial earnings losses upon job loss. These three mechanisms influence match durability and the evolution of surplus values in ongoing matches. It would be useful to integrate these mechanisms into MP models of unemployment fluctuations, which have thus far devoted much greater attention to the forces governing match formation. Robert Topel (1990) and Derek Neal (1995), among others, argue that specific forms of human capital play a central role in determining the magnitude of earnings losses associated with job displacement. Lars Ljungqvist and Thomas Sargent (1998) build an equilibrium 
search model that hardwires a link between job loss and the destruction of human capital, and that includes further human capital depreciation during unemployment.

Workers may also enjoy rents for reasons apart from search-andmatching frictions and returns on specific human capital. Other explanations for worker rents include fairness norms and concerns about pay equity (Akerlof and Yellen 1990), high pay as a device to deter shirking (Bulow and Summers 1986), the appropriation of quasi-rents generated by sunk investments (Grout 1984, Caballero and Hammour 2005), and worker sharing of product market rents. Paul Beaudry and John DiNardo (1991) stress the role of long-term contracting and one-sided commitment as a source of downward wage stickiness. Johannes Schmieder and von Wachter (2010) consider workers who receive higher wages as a consequence of tight labor market conditions in the past. They find evidence that these workers experience higher layoff rates and lose their wage premiums upon job loss, a pattern of results that supports the presence of rents. Whether this pattern accounts for larger earnings losses in recessions, when displacements are more widespread, is an open question.

Workers who enter the labor market in periods of slack conditions suffer negative effects on future earnings that persist for 10 years or more (see, for example, Kahn 2010). Both lasting declines in employer quality and lasting effects of low starting wages on wage growth within firms contribute to the persistent negative earnings effects of slack conditions at entry (see, for example, Oreopoulos, Heisz, and von Wachter forthcoming). These results are interesting in part because new entrants have not accumulated jobspecific rents and are unlikely to have accumulated much in the way of specific human capital. Apparently, weak conditions at the time of labor market entry slow the accumulation of rents and specific human capital for many years thereafter. Similar forces could lower the future earnings prospects of workers who are displaced in recessions and slumps.

ACKNOWLED G M ENTS We thank Bob Hall, Richard Rogerson, the editors, and conference participants for many helpful comments on an earlier draft. April Chen, Olga Deriy, and Gregor Jarosch provided outstanding research assistance. Steven Davis thanks the University of Chicago Booth School of Business for research support. The authors report no conflicts of interest. 


\section{References}

Akerlof, George A., and Janet L. Yellen. 1990. "The Fair Wage-Effort Hypothesis and Unemployment." Quarterly Journal of Economics 105, no. 2: 255-83.

Autor, David H., and Lawrence F. Katz. 1999. "Changes in the Wage Structure and Earnings Inequality." In Handbook of Labor Economics, vol. 3A, edited by O. Ashenfelter and D. Card. Amsterdam: North-Holland.

Bartlesman, Eric J., and Mark Doms. 2000. "Understanding Productivity: Lessons from Longitudinal Microdata." Journal of Economic Literature 38 (September): 569-94.

Beaudry, Paul, and John DiNardo. 1991. "The Effects of Implicit Contracts on the Movement of Wages over the Business Cycle: Evidence from Micro Data." Journal of Political Economy 99, no. 4: 665-88.

Becker, Gary S. 1962. "Investment in Human Capital: A Theoretical Analysis." Journal of Political Economy 70, no. 5, part 2: 9-49.

Binmore, Ken, Ariel Rubinstein, and Asher Wolinsky. 1986. "The Nash Bargaining Solution in Economic Modelling." RAND Journal of Economics 17, no. 2: 176-88.

Blanchard, Olivier J., and Peter Diamond. 1989. "The Beveridge Curve.” BPEA, no. 2: 1-60.

Browning, Martin, and T. F. Crossley. 2001. "Unemployment Insurance Levels and Consumption Changes." Journal of Public Economics 80, no. 1: 1-23.

Bulow, Jeremy I., and Lawrence H. Summers. 1986. "A Theory of Dual Labor Markets with Application to Industrial Policy, Discrimination, and Keynesian Unemployment." Journal of Labor Economics 4, no. 3 (part 1): 376-414.

Burdett, Kenneth, and Dale T. Mortensen. 1998. "Wage Differentials, Employer Size, and Unemployment." International Economic Review 39, no. 2.

Bureau of Labor Statistics. 2010. "Worker Displacement: 2007-2009." News release. USDL-10-1174. www.bls.gov/news.release/disp.nr0.htm.

Burgard, Sarah A., Jennie E. Brand, and James S. House. 2007. "Toward a Better Estimation of the Effect of Job Loss on Health." Journal of Health and Social Behavior 48, no. 4: 369-84.

Burgess, Simon, and Hélène Turon. 2010. "Worker Flows, Job Flows and Unemployment in a Matching Model." European Economic Review 54, no. 3 (April): 393-408.

Caballero, Ricardo J., and Mohamad L. Hammour. 2005. "The Costs of Recessions Revisited: A Reverse-Liquidationist View.” Review of Economic Studies 72, no. 2 (April): 313-41.

Charles, Kerwin Kofi, and Melvin Stephens. 2004. "Disability, Job Displacement and Divorce." Journal of Labor Economics 22, no. 2: 489-522.

Congressional Budget Office. 2004. "Family Income of Unemployment Insurance Recipients." Washington (March).

Costain, J., and M. Reiter. 2008. "Business Cycles, Unemployment Insurance, and the Calibration of Matching Models." Journal of Economic Dynamics and Control 32, no. 4: 1120-55. 
Couch, Kenneth A., and Dana W. Placzek. 2010. "Earnings Losses of Displaced Workers Revisited.” American Economic Review 100, no. 1: 572-89.

Davis, Steven J. 2005. Comment on "Job Loss, Job Finding and Unemployment in the U.S. Economy over the Past Fifty Years" by Robert Hall. NBER Macroeconomics Annual 20: 139-57.

Davis, Steven J., and John Haltiwanger. 1990. "Gross Job Creation and Destruction: Microeconomic Evidence and Macroeconomic Implications." NBER Macroeconomics Annual 5: 123-68.

Davis, Steven J., R. Jason Faberman, and John Haltiwanger. 2006. "The Flow Approach to Labor Markets: New Data Sources and Micro-Macro Linkages." Journal of Economic Perspectives 20, no. 3: 3-26.

- 2012. "Labor Market Flows in the Cross Section and over Time." Journal of Monetary Economics 59, no. 1: 1-18.

Davis, S. J., R. J. Faberman, J. C. Haltiwanger, and I. Rucker. 2010. "Adjusted Estimates of Worker Flows and Job Openings in JOLTS." In Labor in the New Economy, edited by K. Abraham, M. Harper, and J. R. Spletzer. University of Chicago Press.

Den Haan, Wouter, Garey Ramey, and Joel Watson. 2000. "Job Destruction and the Experiences of Displaced Workers." Carnegie-Rochester Conference Series on Public Policy 52: 87-128.

Eliason, M., and D. Storrie. 2009. "Does Job Loss Shorten Life?" Journal of Human Resources 44, no. 2: 277-302.

Elsby, Michael, Ryan Michaels, and Gary Solon. 2009. "The Ins and Out of Cyclical Unemployment." American Economic Journal: Macroeconomics 1, no. 1: 84-110.

Eyigungor, Burcu. 2010. "Specific Capital and Vintage Effects on the Dynamics of Unemployment and Vacancies." American Economic Review 100, no. 3: 1214-37.

Farber, Henry. 1999. "Alternative and Part-Time Employment Arrangements as a Response to Job Loss.” Journal of Labor Economics 17, no. 4, part 2 (October): S142-S169.

Foster, Lucia, John Haltiwanger, and C. J. Krizan. 2001. "Aggregate Productivity Growth: Lessons from Microeconomic Evidence." In New Directions in Productivity Analysis, edited by Edward Dean, Michael Harper, and Charles Hulten. University of Chicago Press.

Frey, Bruno S., and Alois Stutzer. 2002. "What Can Economists Learn from Happiness Research?" Journal of Economic Literature 40, no. 2 (June): 402-35.

Gertler, Mark, and Antonella Trigari. 2009. "Unemployment Fluctuations with Staggered Nash Wage Bargaining." Journal of Political Economy 117, no. 1: 38-86.

Grout, Paul A. 1984. "Investment and Wages in the Absence of Binding Contracts." Econometrica 52 (March): 449-60.

Gruber, Jonathan. 1997. "The Consumption Smoothing Benefits of Unemployment Insurance." American Economic Review 87, no. 1: 192-205. 
Hagedorn, Marcus, and Iourii Manovskii. 2008. "The Cyclical Behavior of Equilibrium Unemployment and Vacancies Revisited." American Economic Review 98, no. 4: $1692-1706$.

Hall, Robert E. 1995. "Lost Jobs.” BPEA, no. 1: 221-73.

. 2005. "Employment Fluctuations with Equilibrium Wage Stickiness." American Economic Review 95, no. 1: 50-65.

Hall, Robert E., and Paul R. Milgrom. 2008. "The Limited Influence of Unemployment on the Wage Bargain." American Economic Review 98, no. 4: 1653-74.

Hertweck, Matthias S. 2010. "Endogenous On-the-Job Search and Frictional Wage Dispersion.” WWZ Discussion Paper no. 2010/02. University of Basel.

Hornstein, Andreas, Per Krusell, and Giovanni L. Violante. 2010. "Frictional Wage Dispersion in Search Models: A Quantitative Assessment." Federal Reserve Bank of Richmond, Princeton University, and New York University (August 10).

Jacobson, Louis, Robert LaLonde, and Daniel Sullivan. 1993. "Earnings Losses of Displaced Workers." American Economic Review 83, no. 4: 685-709.

Jovanovic, Boyan. 1979. "Job Matching and the Theory of Turnover." Journal of Political Economy 87, no. 5: 972-90.

Kahn, Lisa. 2010. "The Long-Term Labor Market Consequence of Graduating College in a Bad Economy." Labor Economics 17, no. 2: 303-16.

Kennan, John. 2009. "Private Information, Wage Bargaining and Employment Fluctuations." Review of Economic Studies 77, no. 2: 633-64.

Kilponen, Juha, and Juuso Vanhala. 2011. "The Sensitivity of Job Destruction to Vintage and Tenure Effects." Bank of Finland Discussion Paper no. 1080, revised. Helsinki.

Kletzer, Lori. 1989. "Returns to Seniority after Permanent Job Loss." American Economic Review 79, no. 3: 536-43.

Kodrzycki, Yolanda K. 2007. "Using Unexpected Recalls to Examine the LongTerm Earnings Effects of Job Displacement." Federal Reserve Bank of Boston Working Paper no. W07-2. Boston, Mass.

Ljungqvist, Lars, and Thomas J. Sargent. 1998. "The European Unemployment Dilemma." Journal of Political Economy 106, no. 3 (June): 514-50.

Meyer, Bruce D., Wallace K. C. Mok, and James X. Sullivan. 2010. "The UnderReporting of Transfers in Household Surveys: Its Nature and Consequences." Working Paper no. 15181. Cambridge, Mass.: National Bureau of Economic Research.

Mortensen, Dale, and Eva Nagypal. 2007. "More on Unemployment and Vacancy Fluctuations." Review of Economic Dynamics 10, no. 3: 327-47.

Mortensen, Dale, and Christopher Pissarides. 1994. "Job Creation and Job Destruction in the Theory of Unemployment." Review of Economic Studies 61 (July): 397-415.

Neal, Derek. 1995. "Industry-Specific Human Capital: Evidence from Displaced Workers.” Journal of Labor Economics 13, no. 4: 653-77. 
Oreopoulos, Philip, Andrew Heisz, and Till von Wachter. Forthcoming. "Shortand Long-Term Career Effects of Graduating in a Recession." American Economic Journal: Applied Economics.

Oreopoulos, Philip, Marianne Page, and Ann Huff Stevens. 2008. "The Intergenerational Effects of Worker Displacement." Journal of Labor Economics 26, no. 3: 455-83.

Pissarides, Christopher. 2009. "The Unemployment Volatility Puzzle: Is Wage Stickiness the Answer?" Econometrica 77, no. 5: 1339-69.

Poletaev, Maxim, and Chris Robinson. 2008. "Human Capital Specificity: Evidence from the Dictionary of Occupational Titles and Displaced Worker Surveys, 1984-2000." Journal of Labor Economics 26, no. 3: 387-420.

Polivka, Anne E., and Stephen M. Miller. 1998. "The CPS after the Redesign: Refocusing the Economic Lens." In Labor Statistics Measurement Issues, edited by John Haltiwanger, Marilyn E. Manser, and Robert Topel. University of Chicago Press for the National Bureau of Economic Research.

Postel-Vinay, Fabien, and Jean-Marc Robin. 2002. "Equilibrium Wage Dispersion with Worker and Employer Heterogeneity." Econometrica 70, no. 6 (November): 2295-2350.

Ramey, Garey. 2008. "Exogenous vs. Endogenous Separations.” Working paper. University of California, San Diego (October).

Rege, Mari, Kjetil Telle, and Mark Votruba. 2009. "The Effect of Plant Downsizing on Disability Pension Utilization." Journal of the European Economic Association 7, no. 4: 754-85.

Robin, Jean-Marc. 2011. "On the Dynamics of Unemployment and Wage Distributions." Econometrica 79, no. 5 (September): 1327-55.

Ruhm, Christopher. 1991. "Are Workers Permanently Scarred by Job Displacements?" American Economic Review 81: 319-23.

Rupp, Kalman, and David Stapleton. 1995. "Determinants of the Growth in the Social Security Administration's Disability Programs: An Overview." Social Security Bulletin 58, no. 4: 43-70.

Schmieder, Johannes, and Till von Wachter. 2010. "Does Wage Persistence Matter for Employment Fluctuations? Evidence from Displaced Workers." American Economic Journal: Applied Economics 2, no. 3: 1-21.

Schmieder, Johannes, Till von Wachter, and Stefan Bender. 2009. "The Effects of Unemployment Insurance on Labor Supply and Search Outcomes: Regression Discontinuity Estimates from Germany.” Department of Economics Discussion Paper Series no. DP0910-08. Columbia University.

Schoeni, Robert, and Michael Dardia. 2003. "Estimates of Earnings Losses of Displaced Workers Using California Administrative Data.” PSC Research Report no. 03-543. Population Studies Center, Institute for Social Research, University of Michigan.

Shimer, Robert. 2004. "The Consequences of Rigid Wages in Search Models." Journal of the European Economic Association 2, no. 2-3: 469-79.

_. 2005. "The Cyclical Behavior of Equilibrium Unemployment and Vacancies." American Economic Review 95, no. 1: 25-49. 
2007. "Reassessing the Ins and Outs of Unemployment." Working Paper no. 13421. Cambridge, Mass.: National Bureau of Economic Research. . 2010. Labor Markets and Business Cycles. Princeton University Press.

Silva, Jose Ignacio, and Manuel Toledo. 2009. "Labor Turnover Costs and the Behavior of Vacancies and Unemployment." Macroeconomic Dynamics 13, S1: 76-96.

Stephens, Melvin, Jr. 2004. "Job Loss Expectations, Realizations, and Household Consumption Behavior." Review of Economics and Statistics 86, no. 1 (February): 253-69.

Stevens, Ann Huff. 1997. "Persistent Effects of Job Displacement: The Importance of Multiple Job Losses." Journal of Labor Economics, 15, no. 1, part 1: 165-88.

Stevens, Ann, and Jesamyn Schaller. 2011. "Short-Run Effects of Parental Job Loss on Children's Academic Achievement." Economics of Education Review 30, no. 2: 289-99.

Sullivan, Daniel, and Till von Wachter. 2009. "Job Displacement and Mortality: An Analysis Using Administrative Data." Quarterly Journal of Economics 124, no. 3: $1265-1306$.

Topel, Robert. 1990. "Specific Capital and Unemployment: Measuring the Costs of Worker Displacement." Carnegie-Rochester Series on Public Policy 33 (Autumn): 181-214.

Von Wachter, Till. 2010. "Long-Term Unemployment: Causes, Consequences and Solutions." Testimony before the Joint Economic Committee of the U.S. Congress, April 29. Columbia University.

Von Wachter, Till, and Elizabeth Weber Handwerker. 2009. "Variation in the Cost of Job Loss by Worker Skill: Evidence Using Matched Data from California, 1991-2000." Columbia University.

Von Wachter, Till, Elizabeth Weber Handwerker, and Andrew Hildreth. 2008. "Estimating the 'True' Cost of Job Loss: Evidence Using Matched Data from California 1991-2000.” Center for Economic Studies Working Paper no. 09-14. Washington: U.S. Bureau of the Census.

Von Wachter, Till, Jae Song, and Joyce Manchester. 2011. "Long-Term Earnings Losses Due to Mass-Layoffs during the 1982 Recession: An Analysis Using Longitudinal Administrative Data from 1974 to 2008." Columbia University.

Wightman, Patrick. 2009. The Effect of Parental Job Loss on Children. Ph.D. dissertation, Irving B. Harris Graduate School of Public Policy Studies, University of Chicago. 


\section{Comments and Discussion}

\section{COMMENT BY}

ROBERT E. HALL The crisis of 2008 and its aftermath caused large increases in the incidence of involuntary job loss and large increases in subsequent earnings losses, as replacement jobs have become much harder to find. In this paper Steven Davis and Till von Wachter contribute to research on this key topic in two ways: by providing a detailed analysis, based on von Wachter's earlier work, of data on the earnings of individual workers following mass layoffs; and by examining the leading class of models of unemployment and labor turnover, that developed by Peter Diamond, Dale Mortensen, and Christopher Pissarides, to compare the consequences of job loss in those models with the findings of the new empirical work.

What do the authors mean by the "cost of job loss"? They measure it as the difference in subsequent earnings between workers who retained their jobs during a mass layoff and those who suffered layoffs. The entire focus is on personal rather than social loss: if workers who are highly paid relative to their productivity suffer layoffs and are immediately hired elsewhere at normal wages and the same productivity, it is a private loss-a transfer of rents-but not a social loss. Measuring the social loss would involve a host of issues for which appropriate data are lacking, and even some, such as the right choice of social welfare function, that bring in deep conceptual disagreements. By defining the "cost of job loss" as they do, the authors pose a question that is potentially answerable based on the excellent data they use.

A related point is that the paper focuses on measuring only the losses caused by mass layoffs rather than those caused by the fundamental underlying forces that result in, among other things, mass layoffs. Again, the reader has to decide how to relate the information the authors extract from the data to the deeper issues of the harm to society from, for example, policy failures that have dramatically increased labor market volatility. The 
authors effectively exploit their comparative advantage in providing good summaries of the sample evidence that economists interested in improving policy need to know about.

As the authors discuss, but seemingly only as an afterthought, individual workers do not suffer layoffs as a result of random selection; the data are drawn from normal experience and not from a controlled experiment. Thus, the issue of potential biases from nonrandom selection arises. Employers have an incentive to discharge workers whose pay is high relative to their productivity. Consider the results of a study comparing the earnings of victims of mass layoffs with the earnings of workers at firms with no mass layoffs. The victims are differentially workers who have high wages relative to productivity. In subsequent employment, these workers are likely to receive pay closer to the norm for their productivity. And the same thing would have happened to them, to some extent, without the layoffs. Thus, not all the decline in earnings observed among layoff victims compared with workers at firms without layoffs is the result of the layoffspart would have occurred anyway. What the statistical procedure measures is the sum of the causal effect and the selection effect. Therefore, comparing laid-off workers with those at firms without layoffs exaggerates the consequences of layoff, because the subsequent wage growth of those not laid off will be faster, on average, than the growth that the layoff victims would have experienced but for the layoff. Productivity is largely unobserved, so the control variables in the regressions do not fully adjust for the problem.

This proposition has a flip side that is helpful in measuring the selection effect. The workers at firms with mass layoffs who are not laid off are also subject to a selection effect. They tend to be the workers with low wages relative to productivity. This condition, too, would tend to disappear over time, so the same statistical procedure applied to compare nonvictims at firms with layoffs with workers at firms without layoffs would show a positive effect after the layoff. It would also tend to show wage declines, relative to workers at firms without layoffs, prior to the layoff.

My figure 1 shows what the results would look like if selection were part of the story. The earnings of victims at layoff firms would tend to rise prior to the layoff, fall dramatically after the layoff, and recover subsequently. The earnings of nonvictims at firms with layoffs would fall prior to the layoffs and rise later, again relative to earnings at nonlayoff firms.

The paper covers this point very briefly, by citing evidence from von Wachter's earlier paper (von Wachter, Song, and Manchester 2011). Rather than compare the victims with the nonvictims, however, that paper compares 
Figure 1. Effects of Selection on Earnings before and after a Mass-Layoff Event

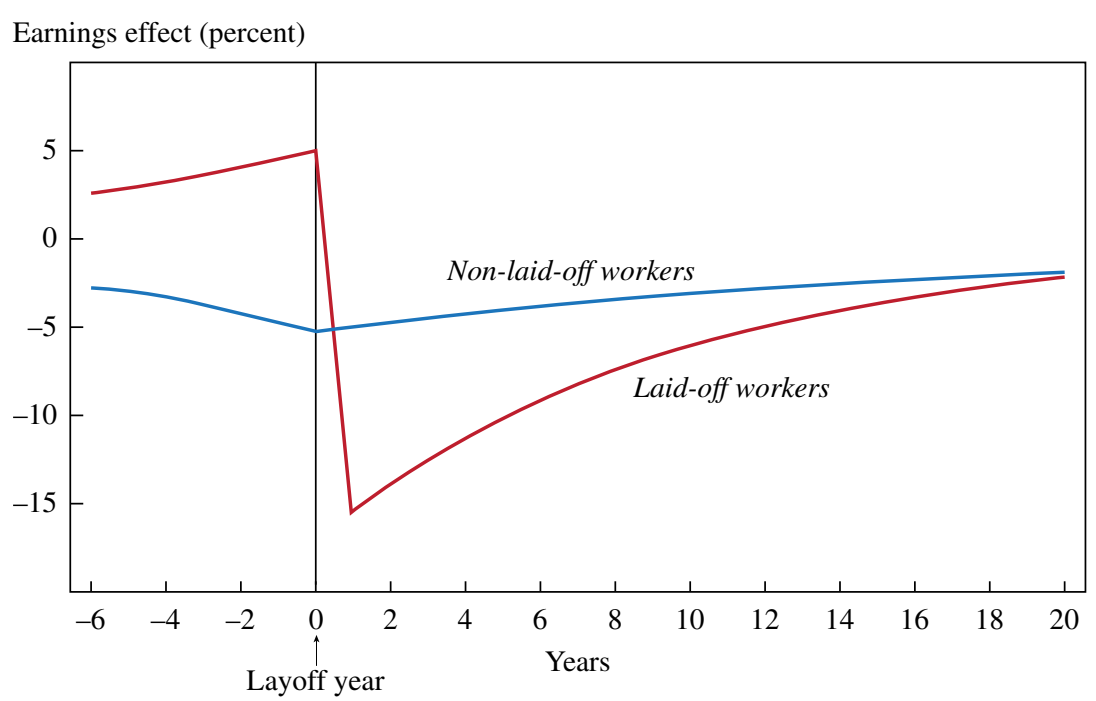

the results for victims alone with the results for all employees of firms with mass layoffs. After adjustment for the fraction of the workers who were victims, the results of the second approach were similar to those for victims only. This is a quite roundabout way of making the comparison I have suggested - their finding implies that no favorable selection effect operated among the nonvictims. As it happens, however, von Wachter did undertake the comparison I had in mind and was kind enough to send me the results, which are presented in figure 2 . That figure shows essentially no effect for nonvictims. Rather than tracking the paths in figure 1, the paths for nonvictims are flat.

Although the evidence in figure 2 is impressive-and surely deserves to be in this paper in place of the brief and opaque summary of the evidence presented instead - it is not completely dispositive, because it rests on the identifying hypothesis that the forces that caused the layoffs had no effects on the firm. Subsequent earnings differences among those not laid off combine the favorable effect of selection with the unfavorable effects of continuing employment at a firm that has suffered a large reversal resulting in mass layoffs. The finding that the nonvictims had roughly zero earnings effects means that the two effects offset each other, not that they are both zero.

Another possibility is that mass layoffs occur in firms that have permanent unobserved characteristics that make them more susceptible to 
Figure 2. Estimated Effects of Mass-Layoff Events on Earnings

Thousands of dollars

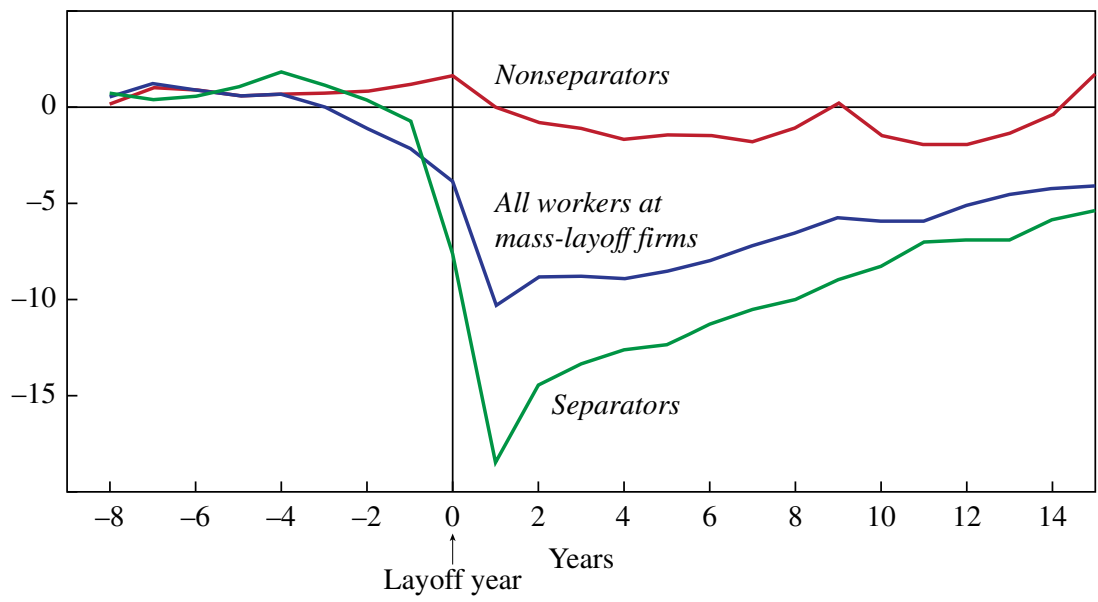

Source: Von Wachter and others (2011, figure 4).

a. Effects are averages (including zeroes) for all men employed continuously during 1974-79 at firms that later experienced a mass layoff. Data are from the 1 percent public-use files of Social Security administrative data.

mass layoffs. Von Wachter and others (2011) test this hypothesis by including firm fixed effects in their regressions. The resulting estimates capture only the earnings losses within the workers of each firm, because the fixed effects pick up differences across firms. Because the within-firm earnings losses remain substantial, although smaller, the authors reach the reasonable conclusion that at least that amount of losses is actually attributable to the mass layoffs.

One way to think about the selection issues in general is to consider the following hypothetical. A survey asks, "At any time in your career, were you laid off from a job that you had held at least 3 years?" An econometrician includes a dummy for a yes answer in a Mincer log wage regression for a sample of 55-year-olds and gets a coefficient of -0.06 with a standard error of 0.01 . Most of us would interpret this finding in terms of a selection-and-unobserved-characteristics story as well as a cost-of-layoff story.

Nonetheless, there is no serious doubt in my mind that a mass layoff inflicts substantial personal earnings losses on its victims for at least a few years and probably more. I think there is more doubt about the permanent loss, which could arise from selection. 
The second major contribution of the paper is to confront the leading model of unemployment and labor turnover-the Diamond-MortensenPissarides (DMP) model — with the findings of substantial earnings losses among victims of mass layoffs. It is easy to explain the basic issue here, although the authors defer this explanation until well into their exposition of the plumbing of the model. Evidence on the cost of recruiting suggests that, right after a new hire, an employer has about $\$ 1,000$ invested in the worker. ${ }^{1}$ The bargaining structure of the DMP model interprets this amount as the employer's capitalized share of the surplus the job generates. If the bargain splits the surplus roughly equally, the worker has a similar stake in the job. The worker's loss from a layoff that occurs immediately after the hire would thus be about $\$ 1,000$, which is far below the figure that the paper calculates for the typical layoff occurring 3 or more years after the hire.

The DMP model as normally developed is focused on unemployment and is exceedingly stripped down with respect to how the typical employment relationship evolves after the hire. All that matters for the analysis of unemployment is the present value of the expected margin the employer will earn from the relationship from the difference between the worker's productivity and the worker's wage. Given the objective of the model, it is no shortcoming that the model cannot generate realistically big figures for the consequences of job loss.

In their conclusion, the authors lay out some of the ideas from labor economics that would belong in a master model of the employment relationship that deals both with the issues that gave rise to the DMP model and with many issues of governance of the ongoing relationship. I think the paper performs an important service in making it clear that the master model faces an important challenge in explaining how workers move from having, on average, only a roughly $\$ 1,000$ stake in a brand-new job to having around $\$ 100,000$ at stake after more than 3 years of tenure. The implied gradient of accumulation of the worker's share of jobspecific capital is remarkably steep, and thus a real challenge to empirical model builders.

1. Hall and Milgrom (2008) report that recruiting cost is 0.43 day of pay per day a vacancy is held open. Daily earnings of the average American worker are $\$ 153$, so the daily vacancy cost is $\$ 66$. According to JOLTS data, it takes 16 days for a vacancy to be filled, so the cost of recruiting one new worker is $16 \times \$ 66=\$ 1,066$. Under the zero-profit condition of the DMP model, the value of the employer's share of the surplus is the cost of recruiting the worker. With a symmetric Nash bargain, the worker's share has the same value. 


\section{REFERENCES FOR THE HALL COMMENT}

Hall, Robert E., and Paul R. Milgrom. 2008. "The Limited Influence of Unemployment on the Wage Bargain." American Economic Review 98, no. 4: 1653-74.

Von Wachter, Till, Jae Song, and Joyce Manchester. 2011. "Long-Term Earnings Losses Due to Mass-Layoffs during the 1982 Recession: An Analysis Using Longitudinal Administrative Data from 1974 to 2008." Columbia University.

\section{COMMENT BY}

RICHARD ROGERSON Steven Davis and Till von Wachter have written a very nice paper that one hopes will motivate much follow-up research. I would summarize the broad theme of the paper as follows. The data reveal a lot of heterogeneity in the nature of unemployment experiences. Although many, perhaps most, unemployment spells are relatively short and seem not to be associated with any persistent negative outcomes beyond the shortterm loss in income, the displacement events that are the authors' focus are associated with substantial long-term losses. ${ }^{1}$ Much recent work on unemployment dynamics has focused on accounting for movements in the level of unemployment and its breakdown into inflows and outflows. Davis and von Wachter argue that a "good" theory of unemployment should account not only for changes in unemployment inflows and outflows but also for the nature of individual unemployment spells, in particular the experiences of the group they define as "displaced workers." They go on to show that a large set of commonly used models of unemployment dynamics fail in this regard. This paper can then be interpreted as issuing a challenge to researchers to develop richer models of wage and unemployment dynamics.

I think this general message is an important one. My comments will focus on two broad points. First, in the context of documenting the facts regarding the earnings losses of displaced workers, I will note some additional information that would be useful to have. Second, regarding the need for models of unemployment dynamics that reflect the experiences of displaced workers, I will argue that the research agenda should be broadened somewhat, relative to what the authors call for. Beyond simply asking the models to also account for the experiences of displaced workers, I think the larger issue is to develop a unified theory of worker flows and wage dynamics more generally.

1. Using quantitative models, Hansen and Imrohoroğlu (1992) show that "typical" unemployment spells have relatively small welfare consequences at the individual level, whereas Rogerson and Schindler (2002) show that displacement of older workers is much more costly at the individual level. 
EARNINGS LOSSES OF DISPLACED WORKERS: EMPIRICAL FINDINGS The previous literature on the earnings losses of displaced workers has documented that workers with at least moderate job tenure who are displaced from medium-size and large firms in mass-layoff events suffer long-lasting decreases in earnings. The authors contribute to this literature by documenting how these losses vary with the state of the economy at the time of displacement. The main finding is that the present value of losses for a worker displaced during a recession is roughly twice that for a worker displaced during an expansion. I think this is an interesting finding, but that some additional information would be valuable, some of which also applies to the earlier literature. I note in advance that, for the most part, I am abstracting from constraints imposed by data availability.

The data used by the authors allow them to measure earnings losses after displacement but do not allow them to decompose these losses into the separate components due to unemployment, reductions in hours in subsequent employment, and reductions in subsequent wages. There is some suggestion that persistent earnings losses are not dominated by the first component, but it is surely relevant for short-term earnings losses, and hence for total present-value losses, and its importance may well vary with the business cycle. In view of the models that the authors consider in section IV of the paper, it is necessarily of interest to know more about the exact role of unemployment in accounting for these losses. Beyond that, there is still a lot of scope for changes in working hours to play a significant role. If they do, it might also be of interest to explore how the change in hours is correlated with other variables. For example, given that many households have two earners, displacement of one member could lead to a reallocation of market work across members. The interesting issue here is the possibility that individuals might choose to work fewer hours after experiencing a displacement, which implies that there is an endogenous component to the earnings losses.

A second issue is that, like most of the related literature, the authors' analysis focuses entirely on mean earnings losses relative to a control group. It would be worth knowing more about the distribution of earnings losses and how they correlate with other factors. If there are compositional differences between displaced workers in expansions and recessions, one would like to know whether these differences can account for the cyclical variation in earnings losses measured by the authors. For example, the authors' data work reveals that recessions are times when relatively more longtenured workers are displaced, and if losses are increasing in tenure, this could explain part of the gap. Similarly, if the ultimate losses depend upon 
how quickly an individual is able to secure employment following displacement, it is of interest to assess the extent to which cyclical changes in unemployment duration can account for the higher earnings losses during recessions. More generally, how does the distribution of losses differ between recessions and expansions? Is there simply a shift in the distribution as one moves through the cycle, or are there notable changes in the shape of the distribution?

Since the measured gap in earnings losses between recessions and expansions reflects changes relative to a control group, it is also relevant to ask what fraction of the gap is accounted for by changes in the control group's earnings. It is certainly possible that the wage gains of the control group are quite different following a recession than following an expansion.

Finally, it is of interest to compare the cyclical gap in earnings losses for displaced workers with other, related measures of how labor market outcomes differ with the state of the business cycle. In particular, a related literature has found that college students who graduate during a recession face persistent earnings losses relative to those who graduate during expansions. Although displaced workers and college graduates are very different populations, they face the common problem of needing to find employment. It would be worth knowing how the magnitudes of these effects compare, and more generally the extent to which these two empirical findings reflect the same underlying economic forces. Put somewhat differently, the cyclical variation in earnings losses for displaced workers may not reflect anything special about displaced workers. Rather, it may simply be that individuals who find themselves in need of a job at a time when aggregate conditions are bad experience substantial long-term earnings losses relative to what the same individuals would experience under better conditions.

EARNINGS LOSSES FOR DISPLACED WORKERS: MODELS Having documented a new fact, the authors next assess the extent to which existing models of labor market dynamics can account for it. This seems a reasonable way to proceed, yet there is a sense in which the authors are getting a little ahead of where the current literature is. Although their main new empirical finding is about the cyclical variation in earnings losses for displaced workers, the fundamental phenomenon of interest is not cyclical in nature. That is, even during periods in which economic aggregates are stable, some longtenured workers are displaced and suffer large and persistent losses in earnings. Even if cyclical variation in earnings losses were the ultimate issue of interest, a natural first test would be to assess whether existing models are able to empirically account for the key features of displacement during stable periods. If they are, one would then proceed to ask whether they 
can also account for the cyclical variation in earnings losses. However, the main conclusion from this part of the paper is that existing models fail the first test. In other words, some benchmark models of unemployment flows are unable to account not only for the authors' new finding but also for key findings of the preexisting literature.

Before commenting on the exact exercises that the authors go through in this section, I want to take a step back and offer a somewhat broader view. In thinking about what types of models offer promise for a better understanding of earnings losses for displaced workers, I think it is important to view the empirical papers on this topic as a subliterature within the broader literature on wage dynamics. One prominent strand of this literature, including, for example, papers by David Card (1994), Martin Floden and Jesper Lindé (2001), and Eric French (2005), uses panel data to estimate statistical models of wage dynamics of the following general form:

$$
\log w_{i t+1}=\bar{w}_{i}+\beta X_{i t+1}+\log z_{i t+1}+\varepsilon_{i t+1},
$$

where $\bar{w}_{i}$ is an individual fixed effect, $X_{i t+1}$ is a vector of observable individual characteristics, $\varepsilon_{i t+1}$ is a random disturbance (possibly measurement error), and $z_{i t+1}$ is a persistent idiosyncratic shock that evolves according to $\log z_{i t+1}=\rho \log z_{i t}+\eta_{i t+1}$, where $\eta_{i t+1}$ is another random disturbance, distributed normally with mean zero and standard deviation $\sigma_{\eta}{ }^{2}$

Although estimates vary among papers in this literature, there is a clear consensus that $\rho$ is close to 1 and that the variance of $\eta$ is substantial. ${ }^{3}$ For example, Floden and Lindé (2001) estimate that $\rho=0.914$ and $\sigma_{\eta}$ $=0.206 .{ }^{4}$ To fix ideas, I adopt these estimates for the $z_{i t}$ process and consider a population of individuals in which everyone is otherwise identical, all of the coefficients in $\beta$ are zero, and the variance of $\varepsilon_{i t}$ is also zero; that is, I assume that $z_{i t}$ is the sole source of earnings dynamics.

2. One limitation of this simple statistical model of earnings dynamics is that it abstracts from the role that worker mobility plays in the process. The phenomenon of displacement that Davis and von Wachter stress is obviously about a strong connection between certain types of worker turnover and earnings shocks. Other papers in the literature have expanded these models to incorporate mobility, but more work is clearly needed.

3. Related to an issue that was raised in the previous section, this literature has studied both earnings and wage dynamics. The main message is that they display similar properties, in that they also exhibit large and persistent idiosyncratic fluctuations. Put somewhat differently, unemployment dynamics account for a very small portion of idiosyncratic changes in earnings.

4. Although Floden and Lindé include individual fixed effects in their specification, in estimation they assume that individual fixed effects are captured by observables and hence are subsumed into $X$. 
To analyze how the literature on earnings losses associated with displacement fits within this framework, I simulate outcomes for a sample of 10,000 workers for 40 years and ask the following question: during the initial 25 years, what fraction of individuals experience a wage decrease of $25 \log$ points that persists for at least 15 years? The answer is 36 percent, or a bit over 1 percent per year on average. If instead one looks for changes that persist for at least 20 years (implying that the focus is now on the initial 20 years), the answer is 22 percent, smaller than the previous number but still a bit larger than 1 percent per year.

These outcomes mimic the kinds of earnings losses that the authors document. But what is noteworthy about this statistical model of wages is that, by symmetry, one will also find that a similar fraction of workers experience a wage increase of $25 \log$ points that persists for at least 15 (or 20) years. A simple but critical message from this exercise is that large and persistent shocks to wages, both positive and negative, are common. Displacement is just one instance of sudden, large, and persistent negative changes, albeit an important one. Put somewhat differently, I think the key to understanding earnings losses for displaced workers in particular is to understand idiosyncratic wage dynamics more generally.

Before proceeding further, it will be useful to think about what the wage shocks in these statistical earnings models represent. There are two key issues. One concerns whether these idiosyncratic shocks are really just proxies for unmeasured heterogeneity. Abstracting from this possibility, the second issue concerns the extent to which these shocks reflect changes in the marginal value product of individuals as opposed to changes in wages holding marginal value product fixed. Sorting these issues out is beyond the scope of this comment, and I will proceed under the assumption that at least a substantial part of these wage shocks reflects changes in wages, holding marginal value products fixed. In what follows I will refer to these shocks as "luck shocks." In the specific case of the earnings losses that the authors measure, I think this interpretation seems reasonable-it is hard to tell a story in which a large group of workers displaced from a given firm experience a negative shock to the true value of their productivity relative to the workers who were not displaced and remained at the firm.

The key point is that the stand that one takes on how to interpret the shocks has implications for what types of models one pursues and the corresponding issues involved. If one interprets them as shocks to the marginal value product of workers, then there is not much of a challenge theoretically. Instead, the key challenge is to document that workers are truly hit with large, persistent shocks to their productivity. Lars Ljungqvist and 
Thomas Sargent (1998) provide one example of a model that stresses idiosyncratic shocks to productivity and can presumably produce outcomes that qualitatively resemble displacement. However, they do not provide any direct evidence on the shocks.

Alternatively, if one interprets the shocks in wage equations as primarily reflecting "luck shocks," the key challenge for modeling is to understand why luck plays such a large and persistent role in wage determination at the individual level. Obviously, a model in which workers are always paid the value of their marginal product will not suffice. A key recent paper in this regard is that by Andreas Hornstein, Per Krusell, and Giovanni Violante (2011), who study the ability of a wide variety of search models to generate substantial variation in wages for identical workers in steady state. Although search is not a necessary ingredient for a theory of wage dispersion, it is a natural candidate to consider, and there is a long tradition of viewing search and wage dispersion as being intimately connected.

With this information as background, let me now comment on the specific exercises that the authors undertake. Because simple search models in the tradition of Dale Mortensen and Christopher Pissarides have become the leading framework for modeling the flows of workers between employment and unemployment, and displacement is a separation between a worker and a firm, it is tempting to think that these simple models are a good starting point for thinking about the earnings losses associated with displacement. However tempting this may be, it turns out to be a poor choice of starting point. I argued previously that the key to understanding the earnings losses of displaced workers is a theory of wage dispersion. But in the steady state of the simplest version of Mortensen-Pissarides models, such as the specification used by Robert Shimer (2005), all workers earn the same wage, and the only source of earnings dynamics is the flow of workers into and out of unemployment. That is, there are no individual wage dynamics in steady state. As such, this type of model is a clear nonstarter for thinking about why identical workers can be paid so differently. Put somewhat differently, although the simplest version of the MortensenPissarides model is useful for thinking about the forces that shape the flows into and out of unemployment, it completely abstracts from the issue of wage dispersion. The richer specification of Mortensen and Pissarides (1994) does include idiosyncratic shocks to match productivity and so does generate some wage dispersion for identical workers in steady state. But as Hornstein and others (2011) show, the extent of dispersion is minimal.

Hornstein and others (2011) argue that from the perspective of generating wage dispersion for identical workers, the most promising search models 
are those that feature on-the-job search. The model by Simon Burgess and Hélène Turon (2010) that Davis and von Wachter study does include onthe-job search and thus is a reasonable starting point. In fact, they show that this model can generate more substantial earnings losses for displaced workers than the earlier models, although far less than what is found in the data. In terms of illustrating the underlying economics, I think a preferable benchmark would be the somewhat simpler and more transparent job ladder model of Kenneth Burdett and Mortensen (1998). ${ }^{5}$

The Burdett-Mortensen search model features identical workers, identical firms, exogenous layoffs, and on-the-job search. In the steady-state equilibrium, firms pay different wages and have different employment levels, with high-wage firms being larger. The model generates simple yet interesting wage dynamics: an unemployed worker accepts the first job offered, and after that accepts any job offer that pays a higher wage. In this sense a worker moves up the job ladder over time. However, because of layoff shocks, workers face a risk of moving back into the unemployment pool and needing to start the ladder over again. Qualitatively, this model seems promising. Getting an offer from a high-wage firm is a persistent positive "luck shock," whereas being laid off is a persistent negative "luck shock," the size of which depends on the worker's wage at the time of layoff. There is a strong connection between the incidence of positive and negative "luck shocks"- the workers who experience the largest negative shocks are exactly those who have previously experienced the largest positive shocks.

Although I think the Burdett-Mortensen model is useful for illustrating some key ideas, it will not be able to generate the persistence of the losses that Davis and von Wachter find in the data, since laid-off workers in this model will move up the earnings distribution just as do workers who enter the labor force for the first time. Put somewhat differently, although I think wage dispersion is intimately related to the earnings losses of displaced workers, a model with sufficient wage dispersion alone is not enough to generate the kinds of persistent losses found by Davis and von Wachter.

Hornstein and others (2011) argue that empirically reasonable versions of this job ladder model can generate roughly an order of magnitude more wage dispersion than the standard Mortensen-Pissarides-style models. Although this is still significantly less dispersion than is found in the data, the calculations in Hornstein and others (2011) suggest substantially more wage dispersion than the Davis-von Wachter calibration of the Burgess-Turon model.

5. See Hornstein and others (2011) for a broader discussion and citations of many other related papers. 
In particular, Davis and von Wachter report that the ratio of the maximum to the minimum wage in their calibrated model is about 1.5, whereas Hornstein and others report that one could justify a calibration of a job ladder model in the spirit of Burdett and Mortensen that can generate a ratio of more than 1.5 for the mean wage relative to the minimum wage. Understanding the economics behind these differences is potentially important. Although greater wage dispersion in this model will presumably lead to greater earnings losses for displaced workers, it is important to note that the calculations carried out by Hornstein and others (2011) do not explicitly relate to the estimated earnings losses of displaced workers.

SUMMARY Davis and von Wachter argue that a good theory of unemployment should necessarily be consistent with the evidence on earnings losses for displaced workers. I am sympathetic to this argument and hope that this paper serves to motivate additional work on developing richer models of labor market dynamics. I would stress two points. First, in my view the most promising direction for building models that can generate substantial earnings losses for displaced workers is to build them in ways that generate substantial wage differences for identical workers. Second, a substantial amount of work remains to be done to build useful and coherent models that can account for the joint behavior of worker flows and earnings dynamics. Although some existing search models are promising in terms of generating wage dispersion for identical workers, factors other than search may also play a role. The importance of unions in the United States is dwindling, but the loss of union jobs may well account for part of the earnings loss for displaced workers. Rigidities in organizational pay structures may also help explain why large gaps can emerge between individual productivity and individual wages. Finally, the models studied in this paper assume that workers are risk neutral. Analysis of the welfare consequences of displacement will surely require a framework that allows for risk-averse workers and asset accumulation.

\section{REFERENCES FOR THE ROGERSON COMMENT}

Burdett, Kenneth, and Dale Mortensen. 1998. "Wage Differentials, Employer Size and Unemployment." International Economic Review 39: 257-73.

Burgess, Simon, and Hélène Turon. 2010. "Worker Flows, Job Flows and Unemployment in a Matching Model." European Economic Review 54: 393-408.

Card, David. 1994. "Intertemporal Labor Supply: An Assessment." In Advances in Econometrics, edited by Christopher Sims. Cambridge University Press.

Floden, Martin, and Jesper Lindé. 2001. "Idiosyncratic Risk in the United States and Sweden: Is There a Role for Government Insurance?" Review of Economic Dynamics 4: 406-37. 
French, Eric 2005. "The Effect of Health, Wealth and Wages on Labour Supply and Retirement Behavior." Review of Economic Studies 72: 395-427.

Hansen, Gary, and Ayşe Imrohoroğlu. 1992. "The Role of Unemployment Insurance in an Economy with Liquidity Constraints and Moral Hazard." Journal of Political Economy 100: 118-42.

Hornstein, Andreas, Per Krusell, and Giovanni Violante. 2011. "Frictional Wage Dispersion in Search Models: A Quantitative Assessment." American Economic Review 101: 2873-98.

Ljungqvist, Lars, and Thomas Sargent. 1998. "The European Unemployment Dilemma." Journal of Political Economy 106: 514-50.

Mortensen, Dale, and Christopher Pissarides. 1994. "Job Creation and Job Destruction in the Theory of Unemployment." Review of Economic Studies 61: 397-415.

Rogerson, Richard, and Martin Schindler. 2002. "The Welfare Cost of Worker Displacement." Journal of Monetary Economics 49: 1213-34.

Shimer, Robert. 2005. "The Cyclical Behavior of Equilibrium Unemployment and Vacancies." American Economic Review 95: 25-49.

GENERAL DISCUSSION Edward Lazear expressed surprise at the result that individuals experience larger losses following job loss during a recession than during an expansion. In theory, he argued, an idiosyncratic job loss during an expansion should send a more negative signal to employers about that worker than the same job loss during a recession, when layoffs are prompted by worsening macroeconomic conditions. That idea led Lazear to wonder whether individuals who lose their job during a recession spend more time out of work than those laid off during an expansion. Such a difference might indicate that greater skill depreciation in the former group is what causes their greater earnings losses.

Lazear then returned to a puzzle brought up by the discussants: if the potential lifetime earnings losses from a recession layoff are so large, why don't these individuals try to make up for some of these losses by investing more in their human capital? He suggested that the lack of evidence of such investment indicated some type of selection effect at work.

Till von Wachter built on Lazear's last comment, arguing that if selection effects were an important source of earnings losses, one would expect that workers laid off idiosyncratically during expansions should experience larger losses than those laid off during recessions. He then reported results of another test of selection effects he had conducted, comparing the earnings losses of workers laid off from firms that eliminated a large fraction of their payrolls with those of other laid-off workers. If selection effects were important, the first group should have experienced smaller earnings losses 
than the second, more of whom were likely to have been laid off idiosyncratically. In the data, however, this turned out not to be the case.

Von Wachter saw this lack of evidence for selection effects as pointing toward a different theory in which cyclical pressures cause an economywide drop in starting wages; when laid-off workers return to work, their wages are recalibrated to this lower level, and these lower wages "stick" to the worker for a long time. In this theory, all workers hired during a recession, whether they were laid off earlier in the recession or not, would experience the persistent negative impacts of starting work during a period with low average wages.

Justin Wolfers was struck by the correlation between the present value of job loss and the unemployment rate. He pointed out that unemployment duration is also correlated with the unemployment rate, and he wondered whether the unemployment rate or the unemployment duration structure was the more important determinant of the present value of job loss. He suggested that an interesting experiment would be to compare the present value of job loss during the recent recession with that in the 1980s recession, since the latter period exhibited a larger unemployment rate shock but a smaller shock to the duration structure.

Christopher Carroll viewed the result that the size and persistence of earnings losses varied across the business cycle as an important contribution to the literature, in part because it could help explain the dynamics of the business cycle. The risk of large, persistent earnings losses amounts to greater uncertainty about future earnings, which might lead individuals to increasing their saving rates, which, in turn, could lead to a shortfall in aggregate demand.

Betsey Stevenson noted that the human capital loss resulting from a layoff could fall into either of two categories: workers might have built up firm-specific capital that they cannot find another employer to make use of, or their general skills might deteriorate quickly during periods of unemployment. The distinction, she argued, was important for policy. If firmspecific skills are the major issue, an appropriate policy response might be to subsidize firms to keep workers employed through downturns. But if atrophy of general skills is the greater concern, a better response might be job training programs aimed at mitigating those skill losses. Responding to Wolfers, Stevenson cautioned against simple comparisons of workers' earnings losses across recessions, since the age structure of the workforce, and thus the average tenure of workers, have changed over time.

John Haltiwanger said that in data he had examined, the duration of joblessness was a strong determinant of wages upon reemployment: separated 
workers who remained jobless for more than a short while experienced much larger wage losses than those who were reemployed quickly. He suggested that the large wage cuts that the long-term unemployed often accept upon reemployment could help explain the higher average persistent earnings losses observed among workers displaced during recessions. Von Wachter countered that he had conducted a similar analysis with German data and did not find large earnings losses to be associated with time spent out of work. Results from separate work with Jae Song and Joyce Manchester using U.S. data suggested that an important predictor of earnings losses following joblessness was switching industries.

Robert Gordon wished the paper had distinguished more carefully between firm-specific human capital and pure economic rent. A piece of evidence in support of the idea that displaced workers suffered significant rent losses, as opposed to loss of firm-specific skills, was the fact that many workers losing mid-level jobs experience earnings losses that far exceed the cost of retraining for a similar job. This suggests that, before being laid off, these workers were being paid much more than their marginal product. A vivid example of this phenomenon is the two-tier wage system at General Motors and Chrysler, in which high-tenured employees are paid double the amount that more recent hires are paid for the same position. Davis responded that the empirical part of the paper was agnostic on the issue of whether rent or firm-specific human capital was a greater source of earnings losses for displaced workers. This agnosticism was deliberate, since he and von Wachter thought the data they examined did not allow them to distinguish between different sources.

Jesse Rothstein expressed skepticism that firm-specific human capital losses could account for anywhere near the magnitude and persistence of earnings losses among those laid off with less than five years of tenure. Why wouldn't these workers rebuild this human capital over the course of several years upon being reemployed?

Von Wachter responded to a query about the average tenure of laid-off workers by explaining that missing data in the early years of the sample made it impossible to compute an overall average. He and Davis had, however, compared workers with different predisplacement job tenure who were displaced during different recessions and found that these workers experienced similar earnings losses. In other words, displaced workers' earnings losses appear to be larger in recessions even for shorter-tenured workers.

Stephanie Aaronson remarked that much of the discussion had focused on the possibility of within-firm selection of individuals for layoff according 
to varying levels of employee rents. She suggested that an alternative type of selection, at the firm level, could be driving the results. Perhaps the division of rents between workers and capital varies at the firm level, for structural reasons such as varying contracting schemes. Then an economy-wide shift of rents from workers to capital during a recession might explain some of the persistent earnings losses that workers experience.

David Romer observed that the labor literature had moved away from the idea that certain aspects of hiring practices, not involving search-andmatching considerations, caused some jobs to pay large, persistent rents, which a worker would lose when laid off. He suggested that one could view this paper as a test of the idea that such rents are significant. He also thought it might be time for researchers to revisit the classic literature on interindustry wage differentials and efficiency wages, in which large, persistent rents are possible. Gregory Mankiw agreed with Romer, adding that it might be worthwhile to add a section to the paper looking at the results from an efficiency wages perspective, to see if it provided a more interesting way of understanding the data than the currently popular MortensenPissarides model.

Steven Davis pointed to an aspect of the data presented by Robert Hall that confounded simple theories of rents or selection to explain persistent earnings losses: for seven consecutive years before the mass-layoff event, the wages of those who ended up being laid off during the recession were virtually the same as those who were not. Von Wachter added that in separate work with Song and Manchester he had tried to predict workers' wage losses based on their moves from high-wage industries to low-wage industries and found that the fraction of total wage losses that they explained was surprisingly low. Losing a job in any industry during a major recession led to large earnings losses.

Robert Shiller suggested that the results could be explained by workers' choices, following a layoff, to move from unpleasant jobs, such as those requiring long hours, to more pleasant ones. Von Wachter agreed that it was reasonable to question the extent to which pure earnings losses translated into utility losses for individuals. To investigate this question, he, Song, and Manchester had examined a range of outcomes, including job stability, health, and children's schooling outcomes, and found that all of these outcomes worsened following job loss. 